Sociologie et sociétés

\title{
Les préjugés et la politique dans l'Amérique d'hier et
} d'aujourd'hui

\section{Prejudice and Politics in the American Past and Present Los prejuicios y la política en los Estados Unidos de hoy y de ayer}

\section{Seymour Martin LIPSET}

Volume 1, numéro 1, mai 1969

URI : https://id.erudit.org/iderudit/001441ar

DOI : https://doi.org/10.7202/001441ar

Aller au sommaire du numéro

\section{Éditeur(s)}

Les Presses de l'Université de Montréal

\section{ISSN}

0038-030X (imprimé)

1492-1375 (numérique)

Découvrir la revue

\section{Citer cet article}

LIPSET, S. M. (1969). Les préjugés et la politique dans l'Amérique d'hier et d'aujourd'hui. Sociologie et sociétés, 1(1), 105-134.

https://doi.org/10.7202/001441ar

\section{Résumé de l'article}

Les extrémismes de droite qui se sont développés aux États-Unis s'expliquent par les changements continuels qui ont bouleversé la structure de la société américaine. De l'analyse historique de ces mouvements se dégage un parallélisme frappant entre les convulsions actuelles de la vie politique américaine et des périodes antérieures marquées par des montées de fanatisme religieux et racial. L'auteur établit la régularité avec laquelle ces extrémismes se sont manifestés et s'attache particulièrement au rôle joué par les préjugés et les théories du complot dans les explications présentées par ces mouvements au sujet des changements sociaux que vivait et vit encore la société américaine. Il s'attache également à élucider les conditions d'émergence de ces mouvements et invoque des raisons qui expliqueraient la courte durée de la plupart d'entre eux, alors même que les facteurs qui leur donnent naissance apparaissent comme des constantes de la vie politique américaine. 


\section{Les préjugés et la politique dans l'Amérique d'hier et d'aujourd'hui*}

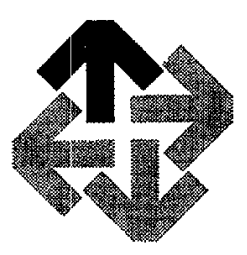

SEYMOUR MARTIN LIPSET

Les TENSIONS sociales qui ont accompagné la croissance économique rapide, l'urbanisation, l'immigration, les migrations internes et la mobilité sociale des différents groupes ethniques tout au long de l'histoire américaine, ont provoqué à maintes reprises l'apparition du phénomène politique du backlash. Plusieurs des groupes qui ont subi ces transformations les ont perçues comme une remise en question de leur statut, de leurs valeurs, ou de leurs intérêts; ils ont réagi en tentant d'éliminer la source de ces menaces, c'est-à-dire la supposée mainmise sur le gouvernement, ou sur les institutions qui régissent le système des communications et la culture, d'une minorité immorale, corrompue et antiaméricaine, dont le pouvoir masqué aurait vidé de son sens le processus de la démocratie formelle. Des mouvements extrémistes, tels que le parti antimaçonnique de la fin des années 1820 , les divers ordres et partis «nativistes» et know-nothing anticatholique de la période précédant la Guerre civile, l'American Protective Association des années 1890, le $\mathrm{Ku}-\mathrm{Klux}-\mathrm{Kl}$ lan des années 1920, le mouvement coughlinite des années 1930, le syndrôme $\mathrm{m}^{\circ}$ carthyiste des années 1950 , et tout dernièrement, le mouvement George Wallace des années 1960, tous ces mouvements ont exprimé, de diverses façons,

* Cet article, traduit de l'anglais par Paul Bernard et Morency Rioux, se fonde sur une recherche en cours qui fournira la matière d'un livre qu'Earl Raab et l'auteur comptent publier en 1969 (Harper and Row) sur la droite radicale américaine, étudiée dans une perspective historique. 
le sentiment de frustration de millions d'Américains qui croient menacés leur influence, leur statut ou leur position économique.

Le recours aux préjugés ethniques, raciaux et religieux contre la menace que représenteraient les groupes minoritaires est un procédé presque aussi vieux que le système politique américain lui-même. Les efforts que la plupart des groupes minoritaires ont déployés aux États-Unis pour améliorer leur situation ont été perçus comme une menace par des groupes de statut social supérieur; à presque toutes les époques, il s'est trouvé des leaders politiques pour faire appel à de tels ressentiments dans l'espoir d'obtenir des suffrages.

Comment de tels réquisitoires extrémistes se cristallisent-ils dans un mouvement ou un parti politique? Si nous prenons pour point de départ le modèle élaboré par Neil Smelser, nous pouvons formuler les propositions suivantes: il doit d'abord exister une tension sociale, ou un déclin dans certains statuts, qui rende la situation quelque peu ambiguë et qui crée un état d'anxiété généralisée. De fait, dans la plupart des cas, les partisans des mouvements extrémistes se sont sentis dépossédés - soit qu'ils n'aient jamais obtenu le pouvoir et le statut qui leur revenaient, soit qu'ils les aient perdus. On pourrait appeler ces deux groupes les « laissés-pourcompte » et les «dépossédés». Ces groupes frustrés ne sont pas nécessairement extrémistes, mais l'extrémisme y puise d'ordinaire sa force. Le premier type, les «laissés-pour-compte », a tendance à ressentir avant tout les privations d'ordre économique, et par conséquent à favoriser des réformes économiques entreprises par l'État; ce mode d'action a très souvent fourni une clientèle à l'extrémisme de gauche, quoiqu'il ait parfois nourri l'extrémisme de droite. Le deuxième type, les "dépossédés", éprouve ou craint une perte de statut ou d'influence. Ce groupe ne peut se satisfaire de mesures gouvernementales; il prend ordinairement une autre direction. Il dirige ses griefs contre un groupe minoritaire et tente de le discréditer ou de le détruire pour soulager sa propre outrance et sa propre anxiété. Cette réaction prend habituellement la forme d'un extrémisme de droite, et c'est le genre d'extrémisme - en tant que préjugé - qui retiendra notre attention.

De telles réactions ne constituent pas simplement une réponse à des changements et à des nécessités d'ordre politique. La fluidité de la structure sociale américaine, le fait que jamais un groupe dominant n'ait pu se voir reconnaître pendant longtemps le même statut social - comme c'est le cas dans certaines sociétés du vieux continent où les statuts et le cloisonnement des classes sont profondément ancrés - tout cela permet de comprendre que le problème de l'insécurité à propos du statut ait été une caractéristique persistante de la vie américaine. De nouvelles régions, de nouvelles industries, de nouveaux groupes migrateurs, de nouveaux groupes ethniques et religieux ont provoqué de continuels bouleversements de la structure sociale. Ces changements ont souvent été accompagnés d'un ajustement des normes qui régissent les relations entre parents et enfants, l'usage des boissons alcooliques et des drogues, les relations entre les sexes, la mode vestimentaire, les conceptions de la moralité religieuse, etc. De tels changements de moralité ont conduit ceux qui adhèrent aux anciennes normes à se sentir déshérités, dépossédés et « dérangés » dans leur propre pays.

Des groupes qui croient avoir droit à un statut et à une influence culturelle, à cause de leurs réalisations passées et présentes, se retournent contre les institutions politiques existantes lorsqu'ils croient que leur droit est mis en question, menacé 
ou en déclin. Dans les conditions actuelles, certains de ces groupes sont relativement privilégiés, tels les médecins ou les chefs d'entreprises familiales, qui ressentent le poids grandissant du pouvoir gouvernemental; parmi les couches sociales moins prospères, on retrouve le groupe de la classe ouvrière blanche qui, après avoir atteint la sécurité économique, sent la pression des revendications des Noirs sur ses écoles, ses quartiers, son syndicat; il y a encore, sur un plan idéologique, les groupes dont l'identité est intimement liée à des valeurs religieuses et profanes traditionnelles en voie d'être supplantées par des idées et des comportements selon eux immoraux. Ce sont là les situations qui typiquement ont permis l'émergence des mouvements de droite, et sans doute de l'extrémisme de droite.

Comment ces groupes dont les valeurs et le statut sont menacés réagissent-ils devant cette insécurité ? Comme le suggère Smelser, ils en disposent en désignant une cause spécifique de la tension - pas nécessairement ni généralement la cause réelle, mais une cause qui leur paraît vraisemblable. Dans plusieurs cas, des groupes que leur ethnie ou leur religion rendent facilement repérables ont très bien fait l'affaire. L'immigration importante de groupes ethniques, qui auraient introduit des valeurs et des modes de comportements antiprotestants et antiaméricains dans la société, a souvent été considérée par des strates « déplacées 》 comme la principale menace qui pesait sur leurs valeurs et leur statut. Par exemple, les malaises économiques ont engendré des mouvements de masse anti-immigrants et anticatholiques parmi les classes défavorisées, qui invoquaient le fait que la concurrence étrangère pour les emplois était la cause du chômage. La perte des élections, la croissance des machines politiques urbaines et les changements dans l'état général de la moralité sociale ont communément été interprétés par les groupes en voie de perdre leur domination économique, sociale, politique ou religieuse, comme étant la faute de groupes étrangers et non protestants, qui auraient miné la structure traditionnelle des statuts et du pouvoir. De même le nativisme, qui a si ouvertement tablé sur l'appel aux groupes ethniques et religieux, a très souvent déterminé l'adhésion de certains groupes ethniques et religieux à un parti politique. Les valeurs que la majorité en déclin a tenté de préserver contre les minorités montantes ont été dans la plupart des cas, aux États-Unis, celles du nativisme, du fondamentalisme et du moralisme simpliste.

Un tel moralisme - qui a cours surtout chez les individus moins instruits, plus fondamentalistes, et plus provinciaux - tient le groupe minoritaire, qui sert de cible, responsable d'une conspiration pour détruire les valeurs mêmes que le groupe dépossédé tente de préserver. Les théoriciens du complot repèrent toujours un noyau tout-puissant d'intellectuels engagés dans une manipulation subversive de la conscience nationale.

Comme nous le verrons, les théories du complot ont été l'arme principale du fanatisme politique aux États-Unis, parce qu'elles suggèrent une stratégie immoédiatement utilisable par le groupe dépourvu: le remède contre la conspiration d'une bande secrète d'intellectuels à la tête d'un groupe minoritaire dont on se méfie, c'est la dénonciation, la répression et même l'annihilation. Et dans bien des cas, ce mode d'action se justifie d'après les canons de la même moralité. Le moralisme fanatique tend à être absolutiste - 1 ' « ennemi » étant identifié avec la littérature corrompue qui circule, et avec la débauche générale. Cette vision politique peu nuancée commande que l'ennemi soit empêché, à cause de sa corrup- 
tion morale et de ses tactiques conspiratrices, de détenir une place légitime dans la vie politique. Tout ce processus peut être appelé la politique du backlash, et il a caractérisé certains secteurs du conservatisme américain pendant une bonne partie de l'histoire du pays.

Dans un premier cas, on voit des fédéralistes de la Nouvelle-Angleterre, des congrégationnalistes et des commerçants qui, réagissant contre leur déclin, découvrent des complots fomentés par des étrangers, et accentuent le rôle de la religion et de la morale. Vers la fin du Xvirr ${ }^{\mathrm{e}}$ siècle, ils ont vu dans les changements de l'ordre moral et la perte concomitante de pouvoir politique, d'influence religieuse et de statut, le résultat d'un complot tramé par les illuminati, une société d'intellectuels affiliée aux maçons qui a existé pendant quelque temps en Bavière.

Des écrivains européens tinrent ce groupe pour responsable de la Révolution française et d'autres soulèvements dans divers pays. L'agitation anti-illuminati visait aussi à contrer le défi jeffersoniste et déiste qui prenait rapidement de l'ampleur et qui menaçait le statut et les valeurs des élites congrégationnalistes et fédéralistes; on accusa les adversaires d'être les agents d'un complot révolutionnaire.

Un quart de siècle plus tard déferla une nouvelle vague d'accusations de conspiration à l'endroit des maçons et, jusqu'à un certain point, des illuminati; c'est au cours d'une période comparable que les forces politiques conservatrices et les forces religieuses traditionnelles se sentirent attaquées par la démocratie jacksonienne montante et par des éléments irréligieux. Le puissant mouvement antimaçonnique s'était assuré une importante clientèle, surtout parmi les couches pauvres et peu instruites de la population rurale, qui vivaient loin des centres urbains; finalement, ces éléments se sont joints aux National Republicans conservateurs pour former le parti whig. Les deux vagues d'agitation contre les conspirations des maçons et des illuminati étaient liées aussi au fanatisme ethnique et religieux. Les illuminati de 1798 furent associés aux activités révolutionnaires des Irlandais dans leur propre pays et en Amérique, tandis que le parti antimaçonnique a eu, par moments, des attitudes nativistes, anticatholiques et même antisémites.

Ces efforts pour attribuer à des complots secrets le fait qu'on croie menacés la religion et les statuts établis, aussi bien que l'exploitation répétée du nativisme anticatholique, par les fédéralistes d'abord, et plus tard par les whigs et les groupes affiliés pendant les deux décennies qui ont précédé la Guerre civile, illustrent, comme nous le verrons, la volonté de certaines couches de l'élite américaine de faire appel à l'extrémisme pour conserver le pouvoir. Dans la masse, la montée de tels mouvements a souvent été la réponse des protestants évangéliques aux changements qui, croyaient-ils, allaient détruire leurs valeurs morales ou leur statut social.

Des premiers jours de la République jusqu'à la Grande Dépression, la source la plus importante de préjugés dans la politique américaine a été l'anticatholicisme. Ce sentiment a des racines religieuses profondes aux États-Unis: les sectes puritaines et protestantes, les méthodistes et les baptistes qui en vinrent à dominer numériquement, tous haïssaient les papistes. Et ce puissant courant de sentiments anticatholiques a été exploité à plusieurs reprises dans l'histoire américaine pour soutenir des mouvements qui cherchaient à préserver les institutions existantes contre la menace du changement - menace qui a été attribuée au nombre élevé de catholiques dans le pays et même à des complots dirigés par Rome. 
La première tentative importante pour exploiter politiquement l'anticatholicisme semble s'être produite à New York au début du XIX ${ }^{e}$ siècle. Le parti fédéraliste, qui venait d'être défait, tenta de refaire ses forces en ranimant les préjugés religieux des électeurs; il se reconstitua en un parti anticatholique, l'American Party ${ }^{1}$, définissant ainsi un modèle de conduite qui a été souvent repris par la suite, et selon lequel les conservateurs font appel au fanatisme racial et religieux lorsqu'ils voient leur pouvoir décliner.

Le premier phénomène politique imputable à l'anticatholicisme s'est produit pendant les années 1830; il coïncidait avec l'accroissement de l'immigration et avec la montée de la démocratie jacksonienne. Pendant ce temps se répandait de plus en plus une propagande anticatholique faisant état de supposés péchés et desseins maléfiques de l'Église, y compris la révélation d'activités sexuelles secrètes qui se seraient déroulées dans les couvents et les monastères (Six Months in a Convent, The Nuns, etc.). Selon ces écrits, les catholiques cherchaient à corrompre et à conquérir l'Amérique par leur simple accroissement numérique, à la suite de l'arrivée de masses d'Irlandais et d'autres immigrants. Des partis catholiques sont nés çà et là dans les villes de l'Est vers les années 1830 et ont crû en nombre et en influence dans la décennie 1840-1850.

Le succès de cette vague d'hystérie anticatholique semble être lié, dans une large mesure, à la faiblesse dans les villes, au cours des années 1830 et 1840 , du parti conservateur principal, celui des whigs. Étant donné l'aide certaine apportée aux démocrates par l'image populiste jacksonienne, les whigs eurent de plus en plus de difficultés à gagner des élections.

Ils commencèrent à attribuer leurs défaites électorales au fait que les étrangers et les catholiques votaient massivement pour les démocrates. Comme de plus en plus d'étrangers, surtout des catholiques arrivaient au pays, plusieurs whigs craignaient d'être incapables de tenir tête à leurs rivaux politiques. Cette crainte les a obligés à plusieurs reprises, depuis le début des années 1840 , à mettre de l'eau dans leur vin. C'est ainsi qu'ils ont eu recours aux préjugés en s'alliant aux forces antipapistes les plus agressives, regroupées dans divers groupuscules nativistes qui prônaient une politique de l'« Amérique aux Américains 》.

L'anticatholicisme des whigs tablait sur certaines craintes et certaines valeurs fondamentales des protestants pour tenter de les éloigner des démocrates: les protestants orthodoxes voyaient dans le nombre grandissant de catholiques et dans leur influence politique croissante en milieu urbain une menace à la domination culturelle protestante. Plusieurs travailleurs protestants percevaient le nombre grandissant d'immigrants, catholiques et autres, comme une concurrence économique et une menace à leur statut. De plus, pendant cette période de croissance démographique et de mobilité géographique, plusieurs protestants déménagèrent des zones rurales vers les zones urbaines, et ce faisant, coupèrent les liens sociaux étroits établis avec les gens et les institutions au milieu desquels ils avaient été élevés; ils craignaient, évidemment, les nouvelles mœurs de la ville. Les protestants redoutaient aussi le résultat des efforts des catholiques qui s'opposaient à l'enseignement du protestantisme et à la lecture de la Bible protestante dans les écoles

1. Ce groupe a été le premier à adopter le nom d'American Party. Sous des formes différentes, le terme American Party a été employé par les racistes et les fanatiques pendant près d'un demi-siècle. 
publiques (les requêtes catholiques recevaient l'appui des libéraux religieux, des déistes et des athées, regroupés surtout dans le parti démocrate).

En exploitant toutes ces craintes de bouleversements économiques, culturels et moraux, les ordres secrets anticatholiques, dotés de rites élaborés, purent recruter des protestants en grand nombre, surtout chez les pauvres et les gens peu instruits, afin de défendre les valeurs et les traditions anciennes. Les écrits de cette période ont non seulement été anticatholiques dans leur ensemble, mais encore y a-t-on élaboré la théorie spécifique d'un complot catholique ourdi à Rome afin de miner le système américain. C'est vraisemblablement la croyance à cette théorie qui justifiait la violence et les moyens non démocratiques employés pour enrayer ce complot. De 1840 au milieu des années 1850 eurent lieu des émeutes anticatholiques; des églises et des couvents furent brûlés et des catholiques furent battus. Au même moment, on blâmait les catholiques pour la criminalité urbaine et pour la croissance de l'immoralité.

Étant donné la logique de l'absolutisme moral, une grande partie des écrits odieux publiés à ciel ouvert et des propos tenus secrètement de nos jours au sujet des Noirs furent formulés au sujet d'autres groupes minoritaires identifiables (surtout les immigrants catholiques) à divers moments avant la Guerre civile. Les thèmes du crime dans la rue, de l'immoralité, de la déchéance et de la conspiration ont été les piliers du régime d'intolérance américain.

Le point culminant de la vague croissante d'anticatholicisme a été l'émergence de l'American Party, ou Know-Nothing Party en 1854. Pendant une courte période, ce dernier était le second parti en importance aux États-Unis, lorsque les whigs cessèrent à toutes fins pratiques de présenter des candidats. Il s'est assuré le pouvoir dans plusieurs villes de l'Est ainsi qu'à Baltimore et à la Nouvelle-Orléans. Ses représentants constituaient les deux tiers de la Législature du Massachusetts et la majorité à la Législature du Connecticut. En fait, le parti know-nothing a conquis l'hégémonie politique dans la plus grande partie de la Nouvelle-Angleterre et dans plusieurs Etats du Centre Atlantique.

Les conditions politiques qui stimulèrent la croissance rapide du parti knownothing ressemblent beaucoup à celles qui étaient liées à la propagation de l'agitation anti-illuminati à la fin des années 1790 et du parti antimaçonnique à la fin des années 1820. À chaque période, la montée en flèche de ces mouvements anticonspiration semble avoir fait suite à l'effondrement des principales forces politiques conservatrices. La frénêsie anti-illuminati a coïncidé avec le déclin du fédéralisme sous John Adams; les antimaçons surgirent lors de la défaite du fils de ce dernier, John Turney Adams, conservateur lui aussi; la montée de la démocratie jacksonienne et l'émergence des know-nothings en tant que mouvement de masse se sont produites après le démembrement du parti whig, à la suite de sa défaite aux élections de 1852.

Même si la plupart des votes de l'American Party provenaient certainement d'anciens partisans whigs, le nouveau parti a pu s'assurer la victoire dans les régions qui votaient traditionnellement pour le parti démocrate, et particulièrement dans les villes, en se ralliant la clientèle de nombreux travailleurs protestants qui avaient voté pour le parti démocrate précédemment. Dans certaines communautés, il a même su se donner une coloration populiste ou gauchiste à propos de diverses questions sociales. 
Cependant, les know-nothings eurent une carrière politique relativement brève. Le parti se démembra en 1857 , avant d'avoir pu faire grand-chose à l'égard des catholiques ou des immigrants. Il a été déchiré par la question de l'esclavage, qui était beaucoup plus importante pour un grand nombre de protestants dévots que ne l'était la cause anticatholique. Les partisans des know-nothings dans les régions du Nord étaient, d'un point de vue religieux, contre l'esclavage, tandis que ceux du Sud y étaient favorables. Un parti aussi divisé sur une question d'une telle importance n'avait plus de raison d'être.

Dans le Nord, les know-nothings furent absorbés par un nouveau parti qui exprimait les sentiments de la communauté protestante de classe moyenne, jadis partisane des whigs; ce nouveau parti était le parti républicain. Après la Guerre civile, le parti républicain devait s'approprier le rôle des know-nothings comme parti anticatholique. C'est ainsi que Ulysses I. Grant fut un know-nothing pendant un court moment. En tant que chef de l'armée de l'Union pendant la Guerre civile, Grant tenta d'interdire les Juifs dans les régions qu'il contrôlait. En tant que Président républicain, il fit des déclarations ouvertement anticatholiques. Prenant la parole à une réunion d'anciens combattants de l'Union, il parla de la menace d'une prochaine guerre civile entre les défenseurs de la superstition (c'est-à-dire les catholiques) et les vrais croyants; il laissa entendre que l'armée de l'Union risquait d'être rappelée pour défendre le pays contre les forces de la superstition. Les deux vice-présidents de Grant avaient été des chefs know-nothings avant la Guerre civile. D'autres présidents et candidats républicains, tels que Rutherford Hayes et James G. Blaine, furent également actifs dans la lutte anticatholique. Sur le plan local, dans les villes, le rôle des républicains comme parti anticatholique était encore plus évident. La déclaration qui aurait entraîné la défaite de Blaine, lors de l'élection présidentielle de 1884, fut celle du Révérend Blanchard qui accusait les démocrates d'être « le parti du rhum, de Rome, et de la rébellion ».

Les historiens se sont si peu rendu compte du rôle de la religion comme source perpétuelle de division politique après la Guerre civile, que ce seul slogan fut cité longtemps après comme ayant été décisif dans le dénouement de l'élection. Cette déclaration n'a cependant pas pu, à elle seule, entraîner la défaite de Blaine, car des milliers de républicains avaient dit des choses semblables ou même plus graves. On peut croire à juste titre que Blanchard a tout simplement résumé ce que beaucoup de républicains disaient tout le temps.

Deux tentatives pour recréer un nouvel American Party échouèrent pendant cette période. La première, lors des élections présidentielles de 1876 et 1880 , ne fut qu'un essai timide de la part de fondamentalistes protestants provinciaux pour faire revivre un mouvement antimaçonnique, teinté d'anticatholicisme. Certains écrits de ce mouvement reliaient les mouvements radicaux de l'heure, tels la Commune de Paris de 1871 et la vague de grèves américaines des années 1870 , à l'activité incessante des illuminati, accusés auparavant d'avoir organisé les révolutions françaises de 1789 et 1830 . Le deuxième American Party de la période qui a suivi la Guerre civile fut formé à la fin des années 1880 et il était surtout anticatholique et nativiste. Malgré sa tentative d'organiser une campagne nationale, ce mouvement ne trouva pas non plus l'appui nécessaire à la formation d'un troisième parti.

En dépit de l'échec des efforts pour mettre sur pied un nouveau parti en exploitant la hantise d'un complot qu'entretenaient les protestants, la situation avait 
suffisamment changé à la fin des années 1880 pour permettre le développement d'un mouvement anticatholique militant, l'American Protective Association (A.P.A.), qui fut fondé en 1887.

Au moment où ses effectifs étaient les plus importants, en 1893, l'A.P.A. et ses organisations affiliées devaient compter environ deux millions de membres. Les tactiques de l'A.P.A. rappelaient celles des know-nothings. Elle ranima les rumeurs que les know-nothings faisaient courir au sujet d'un complot catholique; elle prévint les Américains que les catholiques s'armaient pour prendre le pouvoir et tuer les protestants, et elle accusa les catholiques d'avoir assassiné les présidents Lincoln et Garfield. La ferveur anticatholique était si intense et la théorie du complot si répandue, qu'un homme public responsable, le gouverneur de l'Ohio, distribua des armes aux protestants en 1893 afin qu'ils se défendissent contre la présumée menace que les catholiques faisaient peser sur leur vie. À ce moment-là, l'A.P.A. achetait des fusils et entrainait des troupes, parce qu'elle croyait qu'un de ces jours les catholiques allaient tirer sur les protestants, comme au massacre de la Saint-Barthélémy au XvI siècle en France. Des centaines de milliers de protestants - peut-être des millions - prirent cette affirmation tellement au sérieux qu'ils pensèrent devoir s'armer pour se défendre contre la menace de la minorité catholique. La proportion des catholiques n'était pas plus élevée alors que celle des Noirs aujourd'hui - environ $15 \%$; que $85 \%$ de la population ait craint d'être fusillée dans son sommeil et exterminée par cette minorité, voilà un phénomène étrangement parallèle à la situation contemporaine.

Cette montée dramatique de l'A.P.A. au début des années 1890 , tout comme celle des know-nothings dans les années 1850 , semble avoir été liée aux dangers qui menaçaient de toute évidence le rôle dominant, sur le plan politique, de ce qui était le garant principal de l'autorité évangélique des protestants, soit le parti républicain. Lors des élections au Congrès de 1890 , les républicains subirent leur plus grande défaite depuis la fondation de leur parti; alors qu'ils détenaient auparavant la majorité à la Chambre, ils n'eurent plus que 88 représentants contre 235 démocrates et 9 populistes. En 1892, les démocrates obtinrent leur première majorité décisive depuis 1856 , et un président démocrate fut élu. Ils s'assurèrent également le contrôle politique de plusieurs villes, où des catholiques irlandais commençaient à s'imposer comme maires et chefs politiques. Certaines questions relatives à l'enseignement dans les écoles publiques divisaient toujours protestants et catholiques. Un bon nombre de descendants du premier groupe d'immigrants juifs et catholiques, qui étaient arrivés avant la Guerre civile, étaient maintenant des citoyens prospères de la deuxième ou troisième génération; ils réclamaient l'accès aux institutions du groupe dominant. Pendant les années 1890 vinrent s'ajouter les pressions de l'immigration croissante en provenance de l'Europe, de même que de l'industrialisation et de l'urbanisation rapides. De plus, la dépression de 1893, qui accentua la concurrence pour les rares emplois, accrût à nouveau l'emprise de l'A.P.A. sur la classe ouvrière protestante craintive, qui constituait au moment de son apogée la majeure partie de ses effectifs. L'A.P.A. travaillait surtout dans le cadre du parti républicain (malgré l'appui qu'elle recevait des chefs populistes dans plusieurs régions), tout comme des mouvements nativistes et anticatholiques avaient travaillé dans le cadre du parti whig.

L'A.P.A., comme les know-nothings, n'a été puissante que durant trois ou 
quatre ans; elle déclina par la suite, essentiellement parce que les chefs républicains, dont bon nombre l'appuyèrent pendant que les démocrates étaient au pouvoir, se tournèrent contre elle lorsque leurs propres victoires, écrasantes pendant la dépression, influencèrent les élections au Congrès de 1894. Ce succès, que l'A.P.A. tenta de s'arroger, fit croire aux chefs du parti, comme Mark Hanna, qu'ils avaient maintenant l'occasion de se gagner les voix des catholiques des villes et celles des immigrants s'ils se dissociaient de groupes fanatiques comme l'A.P.A.

La répudiation par les chefs républicains de l'American Protective Association, que certains, tel McKinley, avaient appuyée précédemment, est l'exemple d'un phénomène récurrent dans la vie politique des États-Unis. À certains moments difficiles au point de vue politique, les conservateurs modérés (les whigs ou les républicains) encouragent plus ou moins ouvertement le racisme et l'extrémisme politique afin de gagner à leur cause les couches les moins privilégiées de la clientèle de leurs rivaux démocrates. D'habitude, de telles alliances ont la vie courte, car les modérés tournent généralement le dos aux extrémistes soit à la suite d'un succès électoral, soit à cause de leur aversion grandissante à l'égard du fanatisme de plus en plus avoué des extrémistes.

Bien que l'anticatholicisme fût la source principale du fanatisme religieux au XIX siècle, l'antisémitisme, qui allait devenir si important au $\mathrm{XX}^{\circ}$ siècle, commençait aussi à se manifester. Enraciné dans le sol de l'Amérique rurale, surtout dans l'Ouest, l'antisémitisme apparut d'abord dans les écrits politiques aux États-Unis au cours des années 1870 , comme partie intégrante de la réaction agrarienne à la dépression de 1873 .

Les organisations de protestation agrariennes imputèrent la responsabilité de la baisse des prix agricoles et des autres difficultés économiques des cultivateurs aux banques, qui manipulaient la valeur de l'argent, détenaient les hypothèques des fermes et imposaient un taux d'intérêt élevé sur le marché de New York et sur les marchés internationaux. À la fin $\mathrm{du}^{\mathrm{XIX}} \mathrm{X}^{e}$ siècle, les financiers internationaux qui géraient ces banques étaient souvent personnifiés comme des Juifs; des financiers comrne les Rothschild étaient perçus comme des symboles maléfiques. La propagande du parti populiste des cultivateurs pendant les années 1890 évoquait parfois de sombres complots financiers internationaux qui visaient à détruire l'Amérique; certains des chefs populistes, ainsi que des membres actifs de l'A.P.A., étaient carrément antisémites.

L'A.P.A., comme les know-nothings, exerçait une influence considérable dans les zones urbaines ouvrières, y compris parmi les syndiqués, surtout dans les États de l'Ouest. Eugène Victor Debs, qui était alors le chef du syndicat des cheminots, jugea nécessaire de faire campagne contre l'influence scissionniste de l'A.P.A. dans les rangs du syndicat. Le populisme, qui jouissait d'un appui considérable parmi les protestants évangéliques des zones rurales du Centre-Ouest et du Sud, représentait généralement, malgré ses liens avec l'A.P.A. dans certaines communautés, une forme différente de protestation rurale contre les élites urbaines et cosmopolites de l'Est. Et malgré la présence au sein du mouvement de certains éléments anticatholiques et antisémites, les populistes, dans l'ensemble, voyaient la source de la conspiration qui menaçait leur système social et leur vie en termes de classes économiques, c'est-à-dire dans les activités des banquiers et des hommes d'affaires. En un certain sens, l'A.P.A. aussi bien que les populistes exprimaient la tendance 
des Américains provinciaux éloignés des centres culturels et économiques de l'Est à considérer ceux-ci comme des foyers d'iniquité et d'exploitation économique. Cette tendance à jouer les Américains provinciaux et principalement les protestants ruraux des petites villes contre les élites urbaines, prospères et laïques, est une constante de la vie politique de ce pays. Dans le même sens, d'anciens populistes ont pris pour cible après le tournant du siècle, non plus les élites urbaines en général, mais les catholiques et les Juifs urbains en particulier.

Le représentant le plus remarquable de cette nouvelle orientation du fanatisme fut Tom Watson, qui avait été le principal dirigeant du parti populiste dans le Sud. Watson s'était opposé à la fusion des populistes et des démocrates en 1896. Dans plusieurs journaux, il continua à proférer ses diatribes contre les banquiers, les capitalistes et les gros bonnets des chemins de fer; il en vint aussi à prôner de plus en plus une forme violente de fanatisme racial et religieux, dirigé contre les catholiques, les Juifs, les Noirs. Le journal de Watson, The Jeffersonian, publié dans une petite ville de la Georgie et diffusé par tout le pays, propagea la thèse selon laquelle les Juifs et les catholiques s'étaient unis en une conspiration pour prendre le pouvoir aux États-Unis. Watson se fit surtout connaître, avant que les États-Unis ne s'engagent dans la Première Guerre mondiale, par son rôle de chef de file dans la campagne entreprise pour faire condamner et lyncher un Juif d'Atlanta, Léo Franks, accusé du meurtre d'une jeune fille. Watson se saisit de l'occasion, c'est-à-dire des tentatives des Juifs et des libéraux pour défendre Franks, pour faire la preuve de la conspiration des Juifs prospères en vue d'exploiter et de maltraiter les pauvres chrétiens.

Après la Première Guerre mondiale et pendant la période de prospérité des années 1920 , les États-Unis ont connu leur plus terrible période de répression, symbolisée par la montée du Ku-Klux-Klan, anticatholique, anti-Noir, antisémite et antiintellectuel. Le Klan fut fondé en 1915 par les membres d'une organisation mise sur pied auparavant par Watson pour faire condamner Léo Franks. Dans les années 1920 , on estimait qu'il avait de trois à six millions de membres; le Klan recruta ses membres non seulement dans le Sud mais aussi dans les Etats du Nord; on y comptait des gouverneurs, des maires et des législateurs de tout le pays. Il reçut un appui considérable des villes florissantes du Nord et du Sud, villes qui grandissaient grâce à l'arrivée récente d'immigrants venus des petites villes. Ces migrants tentaient de préserver les valeurs rurales de leur éducation, et ils voyaient dans le Klan un moyen d'assurer « la loi et l'ordre » dans leur nouveau contexte urbain.

Le Klan accusa les catholiques et les Juifs de s'être alliés pour dominer la vie économique et culturelle du pays et de chercher, conjointement avec les communistes, à s'emparer par la force du gouvernement ${ }^{2}$. Le Klan fit aussi revivre les accusations selon lesquelles les catholiques auraient pris part aux meurtres des présidents Lincoln, Garfield et McKinley. Il soutenait même que le président Harding avait été assassiné par des catholiques en 1923 avec une arme secrète et introuvable - l'accusation reposait sur le fait que son certificat de décès portait la mention "cause inconnue » et que l'autopsie n'avait pas été effectuée (on s'en-

2. Durant cette période, c'est moins chez les Noirs que chez les catholiques et les Juifs que l'on voyait une menace; quoique le Klan s'opposât fermement à l'égalité raciale, ses attaques portaient moins, au début des années 1920, sur les Noirs que sur les Juifs et les catholiques. 
tendait généralement pour dire que Harding était mort d'une embolie coronaire). L'antisémitisme était aussi un des leitmotive principaux du Klan. Un chef du Klan soutenait que les banquiers juifs internationaux étaient responsables de la Première Guerre; d'autres accusaient les Juifs d'avoir organisé la révolution bolchévique et de soutenir les communistes partout. Certains chefs du Klan combinaient les thèmes des complots juif et catholique et insinuaient que ces deux groupes s'étaient unis pour prendre le contrôle de la presse, de l'économie et de la vie politique de la nation. New York était pour eux l'exemple d'une ville dépravée, dirigée par les Juifs et les catholiques.

Étant donné leurs craintes à l'égard du changement des valeurs, de l'émergence d'idées «plus libres » et de la détérioration des valeurs religieuses, il n'est pas surprenant que les chefs du Klan aient également attaqué les intellectuels, qu'ils rendaient responsables de la croissance du libéralisme. Un chef du Klan affirmait qu'ils constituaient « une des menaces principales du pays, au lieu d'être des chefs intellectuels sains comme ils devraient l'être. Ils accueillent de façon presque joyeuse la critique par les étrangers de tout ce qui est américain. 》

Quoique le Klan s'en soit pris aux immigrants et aux Noirs, qui étaient dépourvus économiquement, il ne se considérait pas comme le défenseur des privilèges des Blancs protestants. Au contraire, selon Emerson Loucks, les porte-parole du Klan qui eurent le plus de succès constatèrent que le meilleur moyen d'attirer des adhérents était de caractériser «le Blanc protestant autochtone non pas comme membre du groupe dominant et dirigeant..., mais comme appartenant à un groupe de pauvres opprimés, souffrants, pillés par les étrangers, mystifiés par les "Jésuites» et privés de leur droit de naissance par de rusés descendants d'Abraham ${ }^{3}$. Paradoxalement, ils exploitèrent eux aussi « la sympathie que manifeste généralement la masse des Américains pour les opprimés, pour ceux qui pensent qu'ils n'ont pas eu leur juste chance de réussir $\gg$. Aussi le Klan, comme ses prédécesseurs du groupe des antimaçons, se lia-t-il à la tradition anti-élite et égalitaire du pays, tout en répandant le fanatisme.

Durant les années 1920 également, Henry Ford s'affirma comme porte-parole respecté de l'extrémisme de droite et des préjugés religieux. Par la publication d'un journal violemment antisémite, le Dearborn Independent, Ford atteignit plus de sept cent mille lecteurs. Pendant des années, le Dearborn Independent revint sur le thème d'un complot juif international. Une série de 80 articles dans le journal furent réédités sous forme de livre: The International Jew: The World's Foremost Problem. Plus d'un demi-million d'exemplaires de ce livre très nettement antisémite furent distribués aux États-Unis. Les articles arboraient des titres tels que « Jewish Gamblers Corrupt American Baseball», "How the Jewish Song Trust Makes You Sing », «Jew Wires Direct Tammany's Gentile Puppets ", "The Scope of Jewish Dictatorship in America 》, "The Jewish Associates of Benedict Arnold ». Bref, Ford blâmait les Juifs de tout, du communisme au jazz, en passant par l'immoralité et les jupes courtes.

Ford ne présenterait pas grand intérêt pour l'histoire des préjugés politiques s'il n'avait été catapulté comme un des candidats présidentiels possibles en 1923. 1936.

3. Emerson Loucks, The Ku Klux Klan in Pennsylvania, Harrisburg, Telegraph Press, 
Au plus fort de la campagne publicitaire bien orchestrée qu'il mena contre les Juifs, il s'était assuré d'un très large appui dans tout le pays. En fait un des premiers sondages d'opinion publique révéla que $38 \%$ des répondants accordaient leurs suffrages à Ford pour la présidence.

Les activités d'Henry Ford donnaient un caractère dramatique à l'entrée dans l'arène politique américaine d'un antisémitisme de haut vol. Les Juifs étaient très vulnérables à cette nouvelle version de la théorie du complot: car quoique leur nombre ait été grossièrement exagéré, ils étaient effectivement présents dans les cercles capitalistes aussi bien que radicaux. Ils étaient également l'objet des accusations de conspiration qui étaient élaborées à cette époque, pour des raisons politiques, en Allemagne et en Russie tsariste.

Il est intéressant de noter la continuité dans la propagande que répand la droite à propos de supposées conspirations. Le Ku-Klux-Klan réimprima et fit circuler plusieurs livres et récits sur les activités des catholiques qu'avaient utilisés les know-nothings et leurs prédécesseurs. Ford et le Klan répétèrent que les banquiers juifs internationaux tentaient de contrôler et de saper le système financier américain; ces accusations étaient d'abord apparues dans les mouvements agraires et populistes des années 1870 et 1890 . Le fait le plus intéressant fut cependant le rappel continuel du supposé complot des illuminati. Le réputé Christian Science Monitor publia en 1920 un éditorial d'une colonne et demie, intitulé « A Jewish Peril ? », où l'on se demandait sérieusement si les Anciens de Sion ou les illuminati n'appuyaient pas en sous-main divers soulèvements révolutionnaires et l'agitation politique de la Russie jusqu'en Amérique. Le Dearborn Independent rappela à ses lecteurs qu'à deux reprises au cours de l'histoire américaine, des hommes s'étaient rendu compte que le pays était menacé par des forces conspiratrices: en 1798, lors de la première attaque contre les illuminati, et à la fin des années 1820 , au cours de la campagne contre les maçons. Cependant, selon le journal de Ford, ces deux campagnes avaient échoué parce qu'on ne s'était pas rendu compte que les vrais conspirateurs étaient les Juifs et que les illuminati servaient de façade aux Anciens de Sion.

Les années 1920 ne connurent pas que l'apparition de mouvements extrémistes comme le Klan ou celle de têtes d'affiche comme Henry Ford; elles furent également le moment de l'inscription dans la loi du fanatisme racial, ethnique et religieux et de l'absolutisme moral. Ainsi, la période qui va de la fin de la Première Guerre mondiale au milieu des années 1920 vit la promulgation des décrets suivants: une législation restrictive à propos de l'immigration - législation qui non seulement limitait le nombre total des immigrants de façon radicale, mais encore établissait des quotas nationaux de façon évidemment discriminatoire à l'égard des gens qui n'étaient pas du Nord de l'Europe et d'éducation protestante, c'est-à-dire les catholiques et les Juifs; la loi de la prohibition, interdisant les boissons alcooliques; des lois qui, dans certains États, empêchaient les gens de porter des vêtements à caractère religieux dans les écoles qui jouissaient d'une exemption de taxes; et, surtout dans le Sud, des lois qui interdisaient l'enseignement de la théorie de l'évolution.

Ces lois représentaient autant de victoires significatives pour les forces du fondamentalisme, du nativisme, de la xénophobie et du moralisme. Les tentatives pour inscrire ces restrictions nativistes et moralistes dans la loi ont une longue 
histoire, qui remonte presque au début de la République; mais jusqu'aux années 1920 , elles n'eurent pas grand succès. Pourquoi ces croisades ont-elles triomphé durant les années 1920 ? Pourquoi les États-Unis ont-ils succombé à ce moment-là à une vague d'hystérie répressive, nationaliste, moraliste et puritaine ? On ne peut, bien sûr, apporter de réponses absolument certaines à ces questions, mais les analyses qu'ont faites de cette période les historiens et les spécialistes des sciences sociales nous portent à croire que ces mesures de la droite traduisaient la crainte, entretenue dans plusieurs groupes, que le changement social continu finisse par détruire le genre d'Amérique en laquelle ils avaient foi, soit l'Amérique protestante qu'ils vivaient depuis l'enfance.

La croissance des villes représente probablement le signe le plus apparent de ce changement social. La rivalité rurale-urbaine dont nous avons parlé plus haut a été grandement accentuée du fait de l'urbanisation de plus en plus rapide du pays. Le recensement de 1920 révèle que, pour la première fois, la population rurale était devenue minoritaire aux États-Unis. Les grandes villes devinrent manifestement l'axe des communications et de l'influence culturelle. Là également s'établirent de très importants groupes d'immigrants qui venaient de l'Europe non protestante. Des années 1890 à la Première Guerre mondiale, l'immigration fut majoritairement catholique, chrétienne orthodoxe ou juive. Au total, un nombre relativement restreint d'immigrants venaient des pays protestants du Nord de l'Europe. À compter de la Première Guerre, cette affluence s'est traduite par un accroissement du pouvoir politique des catholiques à l'intérieur des organisations démocrates des villes et par le pouvoir qu'acquérait de plus en plus la classe moyenne juive. Les villes qui dominaient la vie économique et politique du pays semblaient être le fief de la masse des immigrants non protestants. Bien sûr, les villes qui croissaient rapidement comptaient aussi un grand nombre de protestants, dont plusieurs étaient des ouvriers venant des régions rurales. Le Klan a bénéficié d'un large support des classes urbaines inférieures, qui bannissaient et tentaient de contrecarrer le pouvoir politique des machines électorales démocrates et le libéralisme culturel des élites urbaines cosmopolites. En dehors des régions urbaines, le Klan recrutait des membres chez les protestants évangéliques qui vivaient dans les petites villes et dans les régions rurales; ceux-ci commençaient à se rendre compte qu'ils étaient des provinciaux isolés, à l'écart des courants importants, tandis que les villes étaient sous la tutelle d'élites qui avaient des valeurs, des attitudes et des coutumes différentes. Comme le formulait en mots saisissants un chef du Ku-Klux-Klan: "Nous sommes devenus des étrangers sur le sol de nos pères. »

Les manifestations antérieures au $\mathrm{xx}^{\mathrm{e}}$ siècle du fanatisme populaire et de la croyance en des théories du complot avaient surgi pendant les périodes d'affaissement du parti qu'appuyaient les protestants évangéliques, les fédéralistes, les whigs et les républicains. L'année 1920 transforma radicalement le destin des partis, mais cette fois ce fut le parti républicain qui connut des gains. Plus de $60 \%$ de l'électorat endossa la politique conservatrice de restauration de Warren Harding, qui s'assura ainsi le plus large appui qu'ait jamais obtenu un républicain; les démocrates, détenteurs du pouvoir, se retrouvèrent avec moins du tiers des voix. Quoique dans le Nord le Klan travaillât le plus souvent au sein du parti républicain, ce n'était assurément pas de la défaillance de celui-ci que le Klan tirait sa force. Il semble plutôt que la montée du Klan, le réquisitoire d'Henry Ford et l'accroissement massif de l'appui aux républicains reflétaient, de différentes façons, le désir 
de plusieurs Américains de restaurer, dans une Amérique transformée par la guerre, par l'urbanisation et par les vagues imposantes de l'immigration non nordique, les valeurs d'une société rurale, protestante et moraliste.

Le parti républicain lui-même s'était adapté au changement d'humeur de ses adhérents. Lors de sa campagne présidentielle de 1920, Warren Harding mit en garde l'Amérique contre les dangers inhérents aux «différences raciales»; il recommanda que les États-Unis n'admettent que les immigrants dont l'éducation indiquait qu'ils pouvaient «s'accorder pleinement aux idées et aux façons de faire américaines ». Son vice-président et successeur à la présidence, Calvin Coolidge, écrivit, peu de temps avant que la nouvelle administration n'entrât en fonctions en 1921, que " les lois biologiques montrent que les Nordiques se détériorent lorsqu'ils sont mêlés aux autres races». James J. Davis, secrétaire au Travail sous Harding et sous Coolidge, continua dans cette veine; il appuya les restrictions à l'immigration en alléguant que les plus vieux «immigrants nordiques arrivés en Amérique tenaient du castor et avaient construit l'Amérique, tandis que les immigrants plus récents étaient des hommes-rats qui tentaient de la détruire; et il est certain que des hommes-rats ne peuvent jamais devenir des castors ». Le dernier de ces trois présidents républicains consécutifs, Herbert Hoover, ajouta sa voix à ce chorus au début des années 1920; alors qu'il était secrétaire au Commerce, il déclara que « les immigrants ne sont à l'heure actuelle que tolérés aux États-Unis... et qu'ils ne le seraient que s'ils se conduisaient bien ».

Se sentant de plus en plus évincés, les républicains protestants des zones non métropolitaines du Nord se joignirent, durant les années 1920, aux démocrates protestants du Sud contre les démocrates des grandes villes. Les fruits de cette première coalition Dixiecrat-Republican furent la prohibition, les restrictions à l'immigration et les autres mesures législatives de répression mentionnées plus haut. Quoique l'on puisse interpréter leurs succès comme un indice de la force de ces groupes de protestants évangéliques et provinciaux, il est probablement plus exact de les considérer comme les signes d'un backlash qui se produisit au moment même où ces groupes perdaient pied. Au cours du XIX ${ }^{e}$ siècle, la plupart des Américains étaient des Blancs, protestants, ruraux ou habitants de petites villes; leurs croyances foncières - nativisme, fondamentalisme, prohibitionnisme - n'étaient généralement pas traduites par la législation. Il a fallu attendre que ce groupe soit à son déclin, alors que d'autres groupes et d'autres valeurs prenaient la relève, pour qu'il trouve l'énergie - engendrée en l'occurrence par la crainte - nécessaire pour établir des législations inspirées de ces valeurs.

Pendant cette période, les droits des dissidents furent vite expédiés. Aussi bien sur le plan fédéral qu'au niveau des États et des localités, des décisions officielles ont réduit les droits de l'opposition politique, au moyen de lois spécifiques, d'investigations législatives et de décrets administratifs. Durant cette chasse aux radicaux, le Secrétariat à la Justice se rendit coupable de perquisitions et de saisies illégales, de mancuvres d'intimidation au cours d'interrogatoires, de demandes de cautionnements excessifs et de refus de la présence d'avocat auprès des inculpés.

Ces actes officiels se doublaient d'actions répressives privées, entre autres l'application de goudron et de plumes et, dans certains cas, le lynchage, la pendaison d'adversaires politiques. Ces adversaires étaient généralement considérés comme 
étant de la «mauvaise » couleur, de la « mauvaise » religion et d'une « mauvaise » ethnie.

L'hystérie des années 1920 disparut progressivement. Elle s'éclipsa en partie, dans le cas du Klan, parce que les causes que celui-ci épousa connurent un succès relatif. Elle déclina aussi parce que les actes de violence et les excès auxquels elle donna lieu conduisirent les éléments les plus respectables de la population, qui l'avaient endossée ou tolérée dans les premiers temps, à la rejeter et à la faire condamner par l'opinion publique. Le Klan perdit beaucoup de ses appuis dans la classe moyenne dès 1924 et il en vint à ne plus être qu'une association en déclin d'ouvriers et de cultivateurs moins instruits. Finalement, il retomba parce que les mouvements de ce genre - comme l'A.P.A. et les know-nothings avant lui étaient composés d'extrémistes qui tendaient à se retourner les uns contre les autres de façon acerbe, agressive et paranoïaque, pour finalement se fractionner. Le dernier sursaut de fanatisme des années 1920 fut la campagne anticatholique extrêmement calomniatrice contre le candidat présidentiel Al Smith, en 1928.

Comme ce fut le cas lors de précédentes montées de fanatisme dans l'opinion publique, l'hystérie ne put se maintenir plus de quelques années; mais la législation adoptée pendant les années 1920 eut des effets durables. La prohibition continua jusqu'en 1933, et elle eut des conséquences désastreuses sur les attitudes à l'égard de la loi et de l'ordre. L'immigration conserva ses quotas discriminatoires jusqu'à récemment. Même si une bonne partie de ces lois ont été abolies par la Cour suprême, quelques-unes sont encore inscrites dans les textes juridiques.

Les années 1930 - marquées par la dépression économique que l'on connaît, par le chômage et les retombées politiques des événements révolutionnaires de l'Europe - connurent également leur part de mouvements extrémistes. Les groupes de droite et de gauche gagnèrent des adhérents pendant cette difficile période. La liste des mouvements de droite profascistes est presque illimitée: les Silver Shorts de William Pelley, la Black Legion du Midwest, les Christian Defenders de Gerald Winrod, la National Union for Social Justice du Père Coughlin, le Committee of One Million de Gerald L.K. Smith et ainsi de suite. Personne ne connait le nombre de membres actifs que réunissaient ces groupes, ni l'ampleur de l'opinion qui leur était favorable.

Des études sur l'appui dont bénéficiaient ces groupes montrent qu'ils attiraient surtout les éléments les plus religieux, les moins instruits et les plus provinciaux parmi les protestants et les catholiques. Les accusations de conspiration étaient dirigées surtout contre les Juifs et les communistes, mais parfois aussi contre les catholiques. Gerald Winrod, un des principaux porte-parole protestants et fondamentalistes, était pronazi, violemment anticatholique et antisémite; il se livrait particulièrement à de sinistres mises en garde contre les Sages de Sion.

Le plus remarquable de ces extrémistes de droite fut un prêtre catholique, Charles Coughlin. Le mouvement coughlinite démontre que plusieurs catholiques pouvaient être tout aussi haineux que les protestants. Ouvertement antisémite et de plus en plus profasciste, le Père Coughlin comptait des millions d'auditeurs à ses émissions radiophoniques hebdomadaires. Les sondages d'opinion publique fiables, qui commencèrent au milieu des années 1930 , révélèrent que les points de vue du Père Coughlin étaient endossés par plus de $25 \%$ de la population adulte. 
Pour plusieurs, son idéologie avait des résonances gauchistes, étant donné qu'il s'opposait fermement à la propriété privée des banques et qu'il rendait responsable de la dépression la recherche du profit par les banquiers internationaux, réputés Juifs pour la plupart.

Fait intéressant, Winrod comme Coughlin croyaient encore à l'existence des illuminati, cette société qui aurait organisé la Révolution française et provoqué l'émergence des mouvements révolutionnaires subséquents, y compris la révolution russe; selon eux, c'était elle qui inspirait maintenant le New Deal. Mais alors que Winrod désigna les illuminati comme source de l'alliance des jésuites et des Juifs pour dominer le monde, Coughlin ne parla pas, bien sûr, de l'engagement des catholiques. Il lia cependant les illuminati, et parfois les maçons, aux tentatives des Sages de Sion et d'autres groupes juifs pour promouvoir le communisme.

Le point culminant de la popularité de Coughlin fut atteint en 1936. Son organisation, la National Union for Social Justice, comptait probablement près d'un million de membres; elle atteignait le reste du pays grâce à sa liaison avec d'autres groupes organisés; une clientèle bien plus imposante encore écoutait d'une oreille sympathique les émissions hebdomadaires dont elle assurait la diffusion. La plupart des candidats au Congrès qui avaient l'appui de Coughlin aux élections primaires de 1936 gagnèrent la lutte pour la nomination. Cependant, Coughlin ébranla la base de sa popularité en tentant de convertir son mouvement en un troisième parti, le Union Party, qui appuya le candidat présidentiel William Lemke. Ce faisant, il se buta à la difficulté classique de telles tentatives, soit leur incapacité d'empêcher bon nombre des électeurs sympathiques à leur cause de fixer leur choix sur celui des deux partis principaux qui représente le «moindre mal». En l'occurrence, plusieurs coughlinites défavorisés, qui profitaient des programmes élaborés du New Deal, choisirent de voter pour Franklin Roosevelt. Lemke, qui avait l'appui de $8 \%$ de l'électorat en juin, selon le sondage Gallup, se retrouva avec moins de $2 \%$ des voix. Sur ce, Coughlin choisit de dissoudre la National Union et de se retirer temporairement de la vie politique. Il revint en scène, peu après, pour former de nouvelles organisations de partisans, mais beaucoup plus petites, et pour proférer des réquisitoires racistes plus explicites et plus virulents; toutefois, il ne se remit jamais de l'échec de la campagne du Union Party.

Plus tard, dans les années 1940 , les coughlinites et une myriade d'autres mouvements fanatiques marquèrent une forte opposition à l'intervention américaine dans la Deuxième Guerre mondiale, à cause de leur tendance à appuyer les nazis. En effet, des sondages d'opinion montrent que près de la moitié de la population avait des attitudes très antisémites au moment où le nazisme battait son plein en Europe. Mais le choc de Pearl Harbor et, dans certains cas, l'action directe du gouvernement firent disparaître ces mouvements pendant la Deuxième Guerre mondiale.

Après la retombée du mouvement de McCarthy, une nuée de petits groupes supplantèrent l'anticatholicisme et l'antisémitisme comme sources les plus manifestes de la croyance en une conspiration. Les assauts les plus importants des racistes durant cette période d'après-guerre remontent à la décision de la Cour suprême à propos de la déségrégation, en 1954. Cette décision provoqua la formation de conseils de citoyens blancs et d'autres groupements visant à freiner la lutte des Noirs pour l'égalité. Le mouvement de droite le plus remarquable au 
début des années 1950 n'était cependant pas raciste. Ce fut le mouvement anticommuniste dirigé par le sénateur Joseph McCarthy qui émergea en 1950. McCarthy porta son attention sur les causes des complots qui faisaient échec à la politique étrangère américaine; ces échecs, disait-il, illustraient le travail d'agents communistes clandestins qui s'étaient infiltrés dans le gouvernement et dans les institutions clés qui informent l'opinion publique et contrôlent l'élaboration des politiques au pays. McCarthy affirmait que ces agents étaient particulièrement bien représentés parmi les élites sociales, les diplômés de Groton et de Harvard, les directeurs de journaux, les professeurs d'universités, les présidents de fondations, le personnel du Département d'État, et ainsi de suite. Il exploita ainsi les tensions virtuelles que l'on trouvait dans les classes inférieures économiquement et socialement et transposa sur un nouveau registre le thème du complot, qui avait caractérisé en grande partie la politique extrémiste américaine. Les résultats de sondages d'opinion publique qui portèrent sur l'appui que recueillait $\mathrm{McCarthy}$ nous indiquent que ce soutien provenait principalement des couches sociales défavorisées, surtout parmi ses coreligionnaires catholiques, de certains groupes ethniques comme les Allemands et les Irlandais, et des régions du pays, le Midwest en particulier, qui s'étaient opposées à l'entrée des Etats-Unis dans la Deuxième Guerre mondiale.

La réaction des chefs modérés du parti républicain envers les groupes extrémistes fut typique du parti conservateur: ils appuyèrent McCarthy jusqu'en 1953, voyant dans ses activités une occasion de gagner l'appui de plusieurs démocrates défavorisés, surtout des catholiques, qui réagissaient violemment contre la montée du communisme à l'étranger et contre le déclin apparent de la puissance mondiale des États-Unis. Richard Rovere interprète ce comportement comme le résultat de la réaction républicaine à la victoire inattendue de Truman sur Dewey aux élections de 1948. Le triomphe des républicains au Congrès en 1946, ainsi que les rapports optimistes des sondages d'opinion publique laissèrent croire aux chefs du parti qu'après 16 ans dans l'opposition, ils allaient enfin accéder au pouvoir. La défaite qui iit suite à cette brusque flambée d'espoir ébranla le respect qu'ils vouaient aux règles conventionnelles du jeu politique, et elle les conduisit, tout comme les fédéralistes et les whigs précédemment, à tolérer et même à encourager l'emploi de tactiques extrémistes. Leur victoire aux élections de 1952 mit fin à la nécessité de recourir à de tels moyens. L'insistance de McCarthy à poursuivre ses attaques contre l'élite gouvernementale, maintenant républicaine, aboutit finalement à sa censure par le Sénat en 1954. Après cela, on le perdit de vue presque complètement; les moyens de communication de masse, qui lui avaient assuré une large publicité, le laissèrent tomber. L'appui de la masse, qui déclinait aussi, faisait peut-être écho aux changements d'attitudes survenus au niveau de l'élite, ainsi qu'à la cessation de la guerre de Corée, qui intervint presque au même moment.

Après la retombée du mouvement de McCarthy, une nuée de petits groupes de droite apparut. Certains d'entre eux ont concentré leur attention sur les Juifs et les communistes, et ont affirmé que le mouvement des droits civils et ses tentatives pour améliorer la situation des Noirs faisaient partie d'un complot juifcommuniste. Le mouvement qui fit le plus de bruit dans les années 1960, la John Birch Society, n'était pas antisémite, mais s'est opposé violemment au mouvement des droits civils. La Birch Society s'est ralliée à la théorie du complot, affirmant que plusieurs des éléments de l'évolution économique et sociale auxquels elle s'opposait étaient le résultat des efforts d'une «conspiration secrète d'insiders », 
c'est-à-dire de nos vieux amis, les illuminati. Elle attribua le développement de l'État providence et la croissance du mouvement des droits civils à un supposé complot communiste dirigé par les illuminati.

Dans un pamphlet, The Truth in Time, Robert Welch, le chef de la société, affirme que les illuminati sont responsables des deux guerres mondiales, de la révolution russe, du démembrement des empires coloniaux, de la formation des Nations unies, du centralisme bancaire, de l'impôt personnel, de l'élection directe des sénateurs aux États-Unis, et de «tout ce qui a rapport à la législation sociale, du premier Workmen's Compensation Act, sous Bismark, à la dernière monstruosité qu'est Medicare, sous Lyndon Johnson ». À l'instar d'Henry Ford, Welch voit une continuité à la fois dans la conspiration et dans l'opposition à celle-ci. C'est pourquoi il s'identifie au mouvement antimaçonnique du début du XIX ${ }^{\mathrm{e}}$ siècle, affirmant que tout comme les illuminati avaient tué William Morgan, un adversaire de la francmaçonnerie dont l'enlèvement et la disparition en 1826 mena à la formation du mouvement antimaçonnique, «ils » avaient aussi éliminé le sénateur Joseph McCarthy, quand celui-ci porta attention à « leurs » activités.

Dans une introduction anonyme à la réédition en 1967 du livre de John Robinson, Proofs of a Conspiracy, publié pour la première fois en 1798, la Birch Society dévoile la supposée identité passée et présente des illuminati:

C'était un complot conçu, organisé et mis en marche par des professionnels et des intellectuels, dont plusieurs étaient brillants, mais rusés et astucieux, et qui décidèrent de mettre leur cerveau au service du mal total... On pourrait croire que les professeurs, les philosophes et les écrivains se réfugient dans leurs tours d'ivoire et ne représentent aucun danger pour le monde. Robinson et l'histoire nous ont prouvé le contraire... De Woodrow Wilson - professeur lui-même - à Lyndon Johnson, nous n'avons eu que des présidents entourés de professeurs et de lettrés... Tout cela nous rappelle le plan de Weishampt d'entourer les autorités dirigeantes de membres de son Ordre.

Dans ses commentaires sur les activités actuelles des illuminati, la Birch Society affirme, dans la même introduction, que ceux-ci ne se servent plus de la francmaçonnerie. "On les retrouve principalement, de nos jours, dans les grandes universités subventionnées, les fondations exemptes d'impôts, les moyens de communications de masse et une myriade d'organisations privées, comme le Council on Foreign Relations ».

En général, la société ne fait pas appel aux fanatismes religieux et racial, et fait porter le gros de son attaque contre les illuminati et leurs agents communistes. Elle a exclu de ses rangs certains membres et des dirigeants importants à cause de leurs activités et prises de positions antisémites. Quoiqu'elle s'oppose fermement à toute tentative pour promouvoir les droits civils ou améliorer la situation socioéconomique de la population noire au moyen d'une action gouvernementale, elle recherche l'appui de Noirs conservateurs, dont elle peut avaliser et appuyer l'action. La teneur de leurs attaques contre le mouvement des droits civils conduit cependant fréquemment les birchers à parler des Noirs et à écrire à leur sujet en des termes qu'il faut qualifier de racistes. Elle reconnaît pleinement aux minorités blanches le droit de gouverner en Afrique du Sud et en Rhodésie, invoquant le fait que ce serait là la seule réponse efficace au communisme et à l'anarchie.

Étant donné qu'elle attaque violemment toute forme d'État providence et de syndicalisme, la société n'a que peu d'attrait pour les défavorisés. L'analyse de la 
composition sociale de ses effectifs, aussi bien que du $6 \%$ de gens, à peu près, qui lors des sondages se révèlent favorables à la Birch Society, nous montre que son appui lui vient d'une strate relativement prospère et bien instruite. Selon une étude des membres de la société par Fred Gruff, Murray Havens et Burton Levy, ceux-ci appartiendraient à la catégorie la moins prestigieuse des gens prospères, ceux qui n'ont pas terminé leurs études universitaires ou qui ont fréquenté des universités moins bien cotées. Tout comme celles de l'A.P.A. et du Klan, les filiales de la Birch Society se retrouvent plus probablement dans les communautés en pleine expansion, surtout dans le Sud et dans l'Ouest.

À cause de l'amalgamation de ces dogmes profondément ultra-conservateurs et de cette croyance en la conspiration, l'organisation est demeurée relativement restreinte (peut-être 60000 membres à son zénith, en 1965) et peu populaire. Reconnaissant la difficulté de gagner un appui important pour le programme dans son ensemble, Robert Welch, le fondateur et le chef de la société, a défini celle-ci comme une organisation d'avant-garde qui s'inspire de la tactique des communistes, c'est-à-dire qui emploie des « organisations de façade » dans lesquelles les membres de la société peuvent devenir des personnages influents.

Le mouvement contemporain le plus puissant et le plus important qui soit lié à ces questions raciales, c'est l'American Independent Party, dirigé par le gouverneur George Wallace, candidat présidentiel en 1968. Presque tous les groupes extrémistes de droite, presque tous les racistes virulents au pays ont donné leur appui à Wallace. Celui-ci a provoqué la plus forte coalition de la droite qui ne se soit jamais produite, du moins au $\mathrm{XX}^{\mathrm{e}}$ siècle. Les membres de la Birch Society, en particulier, jouèrent un rôle primordial dans le parti de Wallace et dans sa campagne d'organisation dans plusieurs États. À la fois lors de sa campagne sous la bannière démocrate aux élections primaires présidentielles de 1964 et au cours de sa tentative récente dans les cadres d'un tiers parti, Wallace fit des déclarations nettement favorables à la Birch Society. Les discours de sa campagne étaient clairs, simples et insistants. Même s'il mentionnait rarement les Noirs comme tels, il se déclara fermement opposé à toute législation gouvernementale qui implique la mise en vigueur de la déségrégation ou la reconnaissance des droits civils dans les domaines du logement, de l'éducation, du syndicalisme, etc. Il parla fréquemment aussi de la nécessité d'employer la force pour restaurer l'ordre et la loi, pour contrôler le crime dans les rues et les émeutes. D'autres thèmes fréquents de ses discours traduisaient sa crainte du pouvoir du gouvernement central en général et son inquiétude devant la faiblesse des États-Unis à l'étranger, en particulier devant leur incapacité de s'assurer une victoire au Vietnam.

Contrairement à la Birch Society cependant, qui est explicitement élitiste, Wallace s'adressa à l'Americain moyen, qui est selon lui plus intelligent et plus honnête que l'élite. Ses héros sont le chauffeur de taxi, l'ouvrier de l'acier, le garagiste et l'homme ordinaire en général. Il voit dans les "pseudo-intellectuels \$, professeurs d'universités, responsables des fondations exemptes d'impôts, éditeurs de journaux et de magazines importants, membres du Council on Foreign Relations et bureaucrates haut placés à Washington, la source du mal et les foyers de diffusion d'une fausse doctrine (ces pseudo-intellectuels ressemblent fort aux illuminati tels que décrits par la Birch Society). Tributaire de la tradition populiste du Sud, il voit dans l' «Establishment de l'Est» le lieu d'origine d'un complot élitiste. Se fondant 
sur le livre du sénateur Joseph McCarthy, il affirme que ce sont des gens prospères qui sont communistes et non des déshérités: «Je ne crois pas tous ces ragots au sujet des pauvres gens qui deviennent communistes. Ce sont les damnés riches qui deviennent communistes. Avez-vous déjà vu un pauvre communiste ? ${ }^{4}$. Fermement opposé à l'appareil judiciaire fédéral, à cause de ses décrets sur l'intégration et les droits des communistes, de même qu'aux avocats de la défense dans les causes criminelles, Wallace endossa la suggestion, d'abord mise de l'avant par les populistes des années 1890, d'élire les juges fédéraux au suffrage universel; cette solution se situe dans le prolongement de sa thèse, maintes fois reprise, de la supériorité morale et intellectuelle de l'homme ordinaire.

Le mouvement de Wallace ne doit pas être pris à la légère. Aux élections de 1968, Wallace reçut l'appui de $13,5 \%$ de l'électorat. Le nom de son parti figurait sur les bulletins électoraux dans tous les États, ce qui n'est pas une mince affaire. C'est certainement la première fois depuis un demi-siècle qu'un tiers parti participe au scrutin dans chaque État, ce qui montre le degré d'organisation et de rodage de ce mouvement. La portée du réquisitoire de Wallace a été encore plus grande que ne l'indiquent les voix qu'il a obtenues. Les sondages Gallup et Harris montrèrent tous deux qu'à la fin de septembre, $21 \%$ de l'électorat le préférait à Humphrey et à Nixon. L'opinion favorable à Wallace déclina régulièrement jusqu'au jour de l'élection et, simultanément, plusieurs de ses partisans, voyant qu'il ne pouvait gagner, commencèrent à se sentir obligés de voter pour le «moindre mal ». En dépit de cette pression, Wallace se révéla capable de retenir un plus grand nombre de ses partisans que n'importe quel autre tiers parti depuis presque un demi-siècle. Notons d'ailleurs que lorsque Gallup, à plusieurs reprises au cours de 1968, demanda aux gens non pas comment ils allaient voter, mais s'ils approuvaient ou désapprouvaient Wallace en général, plus de $40 \%$ indiquèrent leur approbation. Même si l'on compte qu'il a fait le plein de ses voix lors de l'élection — près de dix millions de voix - l'appui dont il jouit n'est pas négligeable.

Wallace trouve son appui dans les mêmes couches sociales que celles qui ont appuyé les mouvements précédents. Il y a une surreprésentation des protestants, ruraux ou habitants des petites villes (quoique sa popularité chez les catholiques soit également considérable). Ses partisans sont en général moins instruits et plus pauvres que la population en général. Outre l'appui des Blancs racistes du Sud, une grande partie de sa clientèle lors de l'élection de 1968 était faite d'ouvriers manuels, dont plusieurs sont des syndiqués. Un sondage spécial auprès des syndiqués, fait en octobre par l'organisation Gallup pour le compte du New York Times, montre qu'au niveau national, $25 \%$ d'entre eux appuyaient Wallace. Un référendum mené auprès des responsables locaux et régionaux de la United Automobile Workers montre que $10 \%$ d'entre eux ont choisi le candidat de l'American Independent Party. Dans le Nord, bon nombre de sections syndicales locales ont même endossé sa candidature. Certains journalistes ont relevé l'inquiétude profonde que suscitait chez les cadres syndicaux l'enthousiasme de leurs membres à l'égard de Wallace.

Plusieurs de ces ouvriers, qui ont un emploi stable, qui achètent leur propre maison dans des quartiers relativement proches des régions noires en expansion, et qui se plaignent des hausses d'impôts, s'opposent à la sécurité sociale, y voyant un

4. Barry Goldwater, "Don't Waste a Vote on Wallace », National Review, 22 octobre 1968, p. $1060-1061$ et 1079 . 
système de taxation de ceux qui travaillent fort au profit des paresseux et des inaptes. Ils font ainsi allusion, dans une large mesure, aux Noirs. Ces syndiqués blancs sont beaucoup plus nombreux à habiter le cour de la ville que les gens de la classe moyenne plus aisée; c'est pourquoi le problème de la croissance du crime urbain et celui des tentatives d'intégration des systèmes scolaires urbains, par la modification de la notion d'école de quartier, les regardent plus directement et plus personnellement. Plusieurs ouvriers croient que les pressions en faveur de la déségrégation des écoles viennent de la classe moyenne bien instruite, qui vit en banlieue ou qui envoie ses enfants aux écoles privées. Pour eux, la question scolaire se résume à ceci: les plus riches font pression sur les ouvriers blancs pour qu'ils envoient leurs enfants aux mêmes écoles que les enfants noirs.

L'appui disproportionné donné à George Wallace par les ouvriers américains se compare au soutien que s'assurèrent précédemment les know-nothings, l'A.P.A., le Ku-Klux-Klan, le Coughlinite Christian Front, et le sénateur McCarthy; il vient contredire l'affirmation de plusieurs selon laquelle la classe ouvrière et le syndicalisme appuient toujours les objectifs de progrès social. Le phénomène d'une classe ouvrière qui endosse le fanatisme en même temps que le syndicalisme et l'État providence corrobore les résultats de plusieurs études sociologiques qui ont révélé que moins les gens sont instruits (et plus, par conséquent, ils sont pauvres), plus il y aura de chances qu'ils aient des préjugés contre les groupes minoritaires, et qu'ils soient intolérants envers la déviance en général. D'un autre côté, cependant, moins un groupe est prospère, plus il favorisera une politique libérale gauchisante en ce qui a trait au statut des syndicats, à la sécurité sociale, à la planification économique, et aux problèmes du même ordre. Les ouvriers et les gens moins prospères votent en général pour les partis libéraux de gauche parce qu'ils estiment que ces partis défendent leurs intérêts économiques et sociaux contre les conservateurs qui représentent, selon eux, la classe aisée et les gros hommes d'affaires. Un candidat qui chercherait à tirer parti de leurs sentiments racistes, mais qui s'opposerait manifestement à leurs intérêts économiques, comme Barry Goldwater en 1964 , ne pourrait gagner leurs voix.

George Wallace, cependant, s'est dérobé à cette alternative, et il a cherché à faire croire que ce sont l' "Establishment de l'Est » et l'élite intellectuelle qui font pression en faveur de l'égalité et de l'intégration des Noirs. Le fait qu'il n'était pas républicain a probablement également contribué à imposer une représentation positive de lui-même aux travailleurs: ceux-ci peuvent plus facilement voter pour un candidat d'un parti qui s'adresse à l'homme ordinaire que pour un candidat et un parti qu'ils assimilent aux gens prospères. Et Wallace a effectivement sollicité un tel appui quand, au plan des mesures d'ordre économique, il a demandé une augmentation immédiate des paiements de sécurité sociale et un doublement de l'exernption personnelle d'impôt, changement dont bénéficieraient plus particulièrement les classes moins aisées. Dans son programme électoral, il a aussi proposé de libéraliser les paiements effectués en vertu du programme Medicare. Fait significatif, un sondage Harris a révélé que la vaste majorité de ses partisans dans le Nord préféraient le terme de « radical » à celui de « conservateur» pour décrire son attitude politique fondamentale.

Comme on pouvait s'y attendre, les sondages d'opinion publique indiquent que les partisans de Wallace dans le Nord venaient principalement des rangs des 
démocrates; et ceux qui ont abandonné Wallace avant le jour de l'élection semblent avoir voté pour Hubert Humphrey. L'analyste politique Samuel Lubell affirma, à la fin d'octobre, que «les électeurs pro-Wallace dans les villes du Nord... expriment des points de vue nettement pro-ouvriers, ce qui les empêche de voter pour les républicains... La plupart de ces partisans de Wallace soutiennent que «Wallace est pour l'ouvrier. Il ne saurait être pour personne d'autre $\gg$. Certains parlent même du mouvement de Wallace comme l'amorce d'un nouveau parti travailliste ${ }^{5}$.

Les policiers, qui constituent un groupe d'occupation à statut relativement bas, étaient très bien représentés, dit-on, dans les rangs des partisans de Wallace. Par ce côté aussi, l'American Independent Party ressemble à ses prédécesseurs de l'extrême droite. Des données relatives à l'appartenance sociale des membres de l'American Protective Association des années 1890, du Ku-Klux-Klan des années 1920 et 1950, de la Black Legion et du Coughlinite Christian Front des années 1930, et de la Birch Society dans les années 1960, ont déjà indiqué l'importance de la représentation des policiers dans leurs rangs.

Plusieurs caractéristiques de leur milieu social d'origine et de leur expérience de travail les prédisposent au fanatisme racial. Comme l'a noté Gunnar Myrdal il y a près de trente ans, ils sont recrutés le plus souvent dans des couches de la population qui sont moins instruites et de statut social assez peu élevé. Une étude récente sur la police de New York révèle que le policier typique est d' « origine ouvrière et qu'il a une instruction de niveau secondaire ou moindre, une intelligence moyenne et un caractère méfiant ${ }^{6}$. Les préjugés contre les Noirs sont plus répandus chez ceux qui viennent d'un tel milieu social. Le travail de la police tend à renforcer et à amplifier de tels sentiments, étant donné qu'il met le policier en contact avec les éléments les plus vils de la communauté noire.

Le rôle du policier est aussi particulièrement propice à l'apparition d'un ressentiment à l'endroit d'une société qui repose sur une inégalité des statuts. D'un côté, en effet, la société lui délègue une autorité considérable pour faire respecter ses lois et s'attend à ce qu'il risque sa vie si cela est nécessaire; d'un autre côté, le policier n'a que peu de prestige et un salaire relativement faible. Bon nombre d'études sur les policiers montrent qu'en général ceux-ci se plaignent de n'être pas respectés du public. Ainsi, les porte-parole des groupes libéraux et gauchistes, de même que les intellectuels, manifestent une hostilité ouverte et même du mépris à l'égard des policiers. Lorsque la police trouve une partie du corps politique qui témoigne quelque appréciation pour sa contribution sociale et pour les risques qu'elle représente, c'est chez les conservateurs et particulièrement à l'extrême droite. Ainsi, le slogan «soutenez votre police locale» a d'abord été formulé par le Ku-Klux-Klan au début des années 1920, puis relancé par la Birch Society dans les années 1960 , et enfin inscrit sur les plaques des automobiles de l'État de l'Alabama par George Wallace au moment où il en était le gouverneur. La Birch Society a institué des récompenses pour les policiers héroïques, et elle a établi une caisse de secours pour les familles de policiers tués au cours de leur travail. George Wallace se donna beaucoup de mal au cours de sa campagne pour louanger la police et dénoncer les critiques des intellectuels libéraux.

5. Samuel Lubell, "New Type Voter Created by Our Economic Boom ", Boston Globe, 27 octobre 1968, p. 24.

6. Arthur Niederhosser, Behind the Shield, Garden City (N.Y.), Doubleday, 1967, p. 38. 
Les jeunes constituent le groupe le plus important parmi ceux qui ont fourni un appui disproportionné à George Wallace. Les sondages Harris et Gallup ont montré qu'en octobre, 25\%, c'est-à-dire un sur quatre des gens âgés de 21 à 29 ans, étaient favorables à Wallace, par comparaison avec les $20 \%$ que l'on comptait parmi les groupes plus âgés. Ce phénomène de l'appui considérable que les jeunes ont accordé à un candidat extrémiste raciste a été passé sous silence par ceux qui ont assimilé la jeunesse américaine aux manifestants gauchistes des campus et aux étudiants bénévoles qui aidaient Kennedy et McCarthy. La nouvelle droite de George Wallace, comme la nouvelle gauche, sont réellement toutes deux les produits du processus de polarisation politique qu'ont provoqué les tentatives de déségrégation, à partir des années 1950. Plusieurs étudiants universitaires de race blanche, qui ont rejoint, au nom du libéralisme, le mouvement des droits civils ont commencé à désespérer de la démocratie américaine lorsqu'ils ont vu les dirigeants sudistes violer: la loi pour préserver la ségrégation. Les tactiques de désobéissance civile et les sit-in sont d'abord apparus, parmi la gauche étudiante, comme une réplique à la désobéissance civile qui était à l'origine le fait des dirigeants blancs ségrégationnistes, comme Ross Barnett au Mississippi, Lester Maddox en Georgie et George Wallace en Alabama. Mais en même temps, plusieurs des jeunes Blancs du Sud et des zones urbaines de classe ouvrière du Nord grandissaient à une époque où la question de l'intégration raciale dans leurs écoles et leurs communautés était brûlante. Ils ont été élevés dans un climat où l'expression de sentiments anti-Noirs à la maison et dans leurs quartiers était chose courante, un climat tel que les membres de la vieille génération entretenaient des craintes quant aux conséquences néfastes de l'intégration résidentielle ou scolaire. Ainsi, tandis que les enfants des parents libéraux de la classe moyenne supérieure s'intégraient à la gauche, la jeunesse de classe ouvrière du Sud et du Nord ralliait la droite.

Ce sont les conséquences de cette polarisation qui se sont manifestées lors de l'élection de 1968. Les indications sur l'attrait qu'exerce le mouvement de Wallace chez les jeunes coïncident avec les résultats de plusieurs études sur les jeunes et la politique estudiantine, selon lesquelles les jeunes sont portés à appuyer la plus extrême ou la plus idéaliste des tendances politiques de leur groupe social. En Europe, les mouvements radicaux de droite et de gauche s'assurent beaucoup plus facilement l'appui des jeunes que les partis démocratiques du centre. Moins engagés dans les institutions existantes et dans les partis que les gens plus âgés, moins habitués à faire des compromis pour atteindre leurs objectifs, les jeunes sont attirés par les mouvements et les dirigeants qui promettent de résoudre rapidement et de façon radicale les problèmes fondamentaux. Malheureusement, nous ne disposons actuellement que de peu d'informations sur l'étendue de l'appui que les mouvements de droite américains précédents ont reçu des jeunes.

La conclusion selon laquelle les préoccupations portant sur la situation raciale et sur la question afférente de "la loi et l'ordre »constituaient le point de convergence des sentiments des partisans de Wallace a été confirmée par les sondages d'opinion publique nationaux. C'est bien là le sens d'une déclaration de Louis Harris: "Le terme commun qui rassemble cet assortiment peu ordinaire d'alliés politiques au cours de cette élection, c'est surtout la race. De tous les partisans de Wallace, $73 \%$ veulent voir s'arrêter le progrès des Noirs. Presque autant, $67 \%$, disent qu'ils se sentent personnellement mal à l'aise face à la perspective d'émeutes raciales dans leur propre communauté. » 
De tels sentiments relatifs aux questions raciales ne constituent pas, bien sûr, le seul facteur qui ait provoqué l'émergence de la nouvelle droite. Le mouvement de Wallace jouit d'un appui important chez les fermiers et les habitants des petites villes, qui sont rarement en contact avec les Noirs. Plusieurs de ces groupes semblent s'inquiéter des transformations que subissent les croyances religieuses et culturelles de l'Amérique. Ils sont souvent des fondamentalistes, laïcs ou religieux. Ils s'opposent à toute altération de la religion du bon vieux temps et ou de l'individualisme traditionnel de l'American Way of Life. Les fondamentalistes religieux, regroupés dans les zones rurales et dans les petites villes, ou parmi les migrants de ces régions dans les grandes villes, se sentent démunis du fait que la société américaine soit devenue cosmopolite et métropolitaine. Les valeurs fondamentalistes sont devenues provinciales et anachroniques aux yeux de ceux qui gèrent les moyens de communication de masse et la vie culturelle du pays. Bien sûr, ces tendances culturelles se sont accentuées avec le temps, et dominent maintenant, dans une large mesure, les principaux courants théologiques, à la fois chez les protestants et chez les catholiques. Et ce groupe de chrétiens traditionalistes, maintenant définitivement minoritaire, est devenu la base principale de l'appui que reçoit une politique dont les thèmes dominants sont l'aliénation et la nostalgie. $\grave{A}$ cette aversion des fondamentalistes religieux se joint celle de plusieurs personnes qui, quoique peu religieuses, sont profondément troublées par le changement des valeurs profanes.

Cependant, on doit noter qu'à l'exception de cette minorité d'extrémistes engagés, le mouvement de Wallace comme tel n'a pas réussi à opérer une percée significative chez les conservateurs prospères et mieux instruits des classes moyenne et supérieure. Un sondage national d'opinion publique effectué par The New York Times, à la mi-octobre, parmi les présidents de toutes les compagnies dont les parts sont cotées à la Bourse de New York, et mené au moyen d'un questionnaire anonyme, nous révèle que moins de $0,5 \%$ d'entre eux, soit trois individus, appuyaient Wallace, tandis que $85 \%$ favorisaient Nixon, et $13 \%$ Humphrey. Bien que Wallace ait joui d'un appui plus marqué auprès des couches inférieures de la catégorie des hommes d'affaires et des professionnels, surtout dans le Sud, les sondages montrent clairement que cette strate lui était quand même opposée d'une façon générale. La plupart de ces gens, même s'ils sont conservateurs au plan économique, ne craignent pas que le pays tombe aux mains des Noirs ou des autres groupes minoritaires, et ils ne sont pas isolés de la vie politique. Dans la mesure où ils accordent de l'importance à la politique, ils militent dans les rangs du parti républicain. En Californie, en 1966, ils se sont ralliés à Ronald Reagan, qui incarne ces vertus conservatrices. Sur le plan local et au Congrès, ils ont pu trouver en 1968 plusieurs candidats aux opinions analogues au sein même du G.O.P. Richard Nixon (qui donna son appui à Goldwater en 1964 et qui fut à son tour appuyé fermement par ce dernier avant la convention républicaine de 1968), même s'il n'est pas aussi conservateur que certains le souhaiteraient, était cependant suffisamment apparenté à de tels points de vue pour s'assurer leur appui.

Le mouvement Wallace n'est sûrement pas de tendance conservatrice. C'est plutôt un mouvement d'adhérents qui ont la nostalgie d'un fondamentalisme religieux et profane. Il s'adresse à ceux qui se sentent réellement menacés par la montée des Noirs dans les villes, par les changements de l'ordre social dont la télévision leur apporte quotidiennement le témoignage, par la transformation continuelle du 
protestantisme et du catholicisme, par les mini-jupes et par le déclin des États-Unis sur la scène mondiale. Ces individus frustrés sont nombreux aux États-Unis aujourd'hui. George Wallace a trouvé le moyen d'en atteindre plusieurs. Il tente réellement de construire un mouvement « poujadiste» avec ces gens qui rejettent le « modernisme».

Les mouvements réactionnaires des années 1960 - le mouvement Wallace, la Birch Society, la Christian Crusade de Billy James Hargis, et d'autres - ressemblent à la poussée du backlash qui a balayé le pays pendant les années 1920 . Aujourd'hui, comme pendant les années 1920 , bon nombre d'individus demeurent en marge des tendances culturelles principales de la société et sont remplis d'amertume face au déclin de la moralité chrétienne traditionnelle. Il reste à voir jusqu'où ira leur puissance cette fois-ci. Certes, leurs effectifs, qui se recrutent chez les fondamentalistes des petites villes et des régions rurales, ne constituent plus une quasi-majorité, comme pendant les années 1920; ce n'est plus qu'une minorité restreinte. Mais les descendants des immigrants des grandes villes se sont joints à ce groupe. Plusieurs d'entre eux sont des catholiques que menacent les progrès réalisés par les Noirs; ils réagissent aujourd'hui à la croissance de la population noire des villes tout comme les ouvriers protestants blancs ont réagi à l'immigration catholique au XIX siècle.

L'hostilité raciale des fondamentalistes provinciaux et protestants, de ceux d'entre eux qui ont déménagé dans les grandes villes et des enfants des immigrants, joue un rôle important dans le réalignement des forces politiques aux États-Unis durant les années 1960 . Une fois de plus, leur amertume a contribué à grossir les rangs du plus conservateur des deux principaux partis, tout en rendant possible l'essor de partis et de mouvements explicitement racistes. Les craintes de ces gens ont été reprises à leur compte, ces récentes années, par plusieurs candidats à la mairie, notamment Louise Day Hicks à Boston, et par bon nombre de républicains de droite importants, qui ont indirectement fait appel à des sentiments racistes en parlant des dangers du crime dans les rues, des émeutes ou de la législation sur la déségrégation de l'habitation. Ils peuvent dire sans ambiguïté, comme l'a fait $\mathrm{M}^{\text {me }}$ Hicks, même si plusieurs d'entre eux n'ont pas ouvertement parlé des Noirs ou du problème racial: "Vous connaissez mes positions. 》

À ce propos, nous devons mentionner qu'un chef républicain, Richard Nixon, a voulu renforcer son parti de l'apport des démocrates traditionnels en cherchant à s'annexer ceux qui s'étaient montrés prêts à abandonner leur ancienne allégeance en faveur d'un candidat raciste. Comme l'a dit The New York Times (12 octobre 1968 , p. 10E), en employant le slogan Wallace: «Donnez votre appui à l'Amérique », il a fait la louange du sénateur Strom Thurmond (candidat présidentiel lors d'une tentative précédente en vue de créer un tiers parti ségrégationniste, en 1948 ) en affirmant que « c'était un homme qui avait défendu son État et défendra l'Amérique, et [qu'il était] fier d'être à ses côtés aujourd'hui ». Plusieurs analystes de l'élection de 1968 ont affirmé que les tactiques de la campagne du candidat républicain à la vice-présidence, Spiro Agnew, semblaient une tentative d'être «plus Wallace que Wallace». À plusieurs reprises, il parla en termes fort énergiques de la nécessité d'éliminer tout ce qui mettait en danger la loi et l'ordre; il expliqua le fait qu'il ne portait pas sa campagne dans les zones noires en disant: « si vous avez vu un ghetto, vous les avez tous vus... »; il décrivit Hubert Humphrey 
comme «porté sur le communisme» et il attaqua «les pseudo-intellectuels [la cible favorite de Wallace] qui ne comprennent pas ce que nous voulons dire lorsque nous parlons d'assiduité au travail et de patriotisme». Étant donné qu'Agnew a conservé cette image à la Wallace pendant toute la campagne, on peut présumer qu'il remplissait un rôle désigné par les stratèges du parti: montrer aux partisans de Wallace qu'ils pouvaient obtenir ce qu'ils voulaient du parti républicain. En somme, la conséquence principale du mouvement Wallace c'est tout probablement que, tout comme les partis antimaçonnique et know-nothing, il servira de courroie de transmission pour amener les démocrates les plus fanatiques au parti conservateur de l'opposition, qui adaptera sa politique pour s'ajuster à leurs préoccupations.

Cependant, il y a le danger bien réel que George Wallace tente de mobiliser ses partisans dans un mouvement de masse qui, comme les précédents, usera de tactiques de confrontation extra-parlementaires, y compris la descente dans la rue pour intimider ses adversaires. Pendant la campagne, il évoqua publiquement la possibilité d'une « révolution blanche» qui, si lui-même était vaincu, tenterait d'obliger les gouvernements des États à "prendre en main les écoles par la force physique » pour en empêcher la déségrégation. Ainsi qu'il a décrit le processus, il y aurait d'abord des rencontres massives et des manifestations de protestation par tout le pays. La vigueur de ces manifestations obligerait les États à mettre un frein à l'ingérence fédérale dans la politique scolaire locale. Wallace s'est dit convaincu que les gens ordinaires sont prêts à une action radicale et il se vante du fait que plusieurs des auditoires pendant sa campagne sont devenus hystériques lorsqu'il parlait de loi et d'ordre et d'intégration scolaire. Il est évident que Wallace a songé à transformer son parti électoral en un mouvement de masse, qui descendra dans les rues pour contrecarrer les activités des «anarchistes》, les manifestations et les émeutes dans les ghettos et sur les campus. Une entreprise de cette nature aurait des implications évidentes quant à l'avenir de la démocratie politique aux États-Unis.

Comme dernier aspect de cette évaluation, il est important de se rendre compte que tous les mouvements précédents dont nous avons parlé ont eu la vie courte, même si des millions de personnes ont été mêlées aux activités de la plupart d'entre eux. Divers analystes ont expliqué leur apparition par la présence de processus endémiques générateurs de tensions; mais dans la logique de ce type d'explications, l'existence de plusieurs de ces mouvements aurait dû se poursuivre plus longtemps que ce ne fut le cas, puisque les conditions qui leur auraient donné naissance ont continué d'exister après leur disparition ou leur déclin. Or, les antimaçons connurent leurs plus beaux jours de 1828 à 1832. Le Know-Nothing American Party a pu gagner des élections dans plusieurs États de 1854 à 1857, mais s'éclipsa rapidement après cela. L'American Protective Association rallia plusieurs millions de personnes entre 1887 et 1894, mais se désagrégea en 1896. Le Ku-Klux-Klan aurait recruté près de quatre millions de membres entre 1921 et 1924, et il réussit à faire élire plusieurs gouverneurs et autres personnages officiels. Il a représenté une force importante aux conventions nationales des deux principaux partis en 1924. En 1925, il perdit beaucoup de ses membres, et à la fin des années 1920, il ne formait plus qu'un petit groupe. Les deux mouvements les plus importants des années 1930 , qui jouissaient d'une popularité considérable selon les sondages d'opinion, ont été le mouvement Share-Our-Wealth de Huey Long et 
les organisations coughlinites. Le mouvement de Long, formé en 1934, disparut complètement lors de l'assassinat de celui-ci en 1935; son premier lieutenant, Gerald L. K. Smith, n'a pu trouver qu'une poignée de gens qui voulaient bien le suivre. L'apogée de Coughlin, quant au nombre des membres et à l'appui populaire, se situe en 1936. Par la suite, son mouvement périclita, puis retomba dans le néant après Pearl Harbor. Le phénomène connu sous le nom de $\mathrm{m}^{\mathrm{c}} \mathrm{car}$ thyisme dura quatre ans, de 1950 à 1954.

Comme on le voit à la lecture de ce compte rendu, il s'avère nécessaire de déterminer non seulement les conditions qui ont permis à différents groupes d'Américains de former et de rallier des mouvements qui s'écartent fort du « consensus » américain, mais aussi les raisons pour lesquelles ces mouvements déclinent si rapidement. Certains d'entre eux, c'est-à-dire les antimaçons et peut-être le $\mathrm{Ku}$ Klux-Klan, s'éclipsèrent au moment où ils semblaient avoir atteint leurs objectifs les plus pressants. D'autres, comme l'A.P.A., le Klan et le $\mathrm{m}^{\mathrm{c}}$ carthyisme, déclinèrent lorsque se retournèrent contre eux certains éléments de la classe aisée qui les avalent d'abord appuyés; ce retournement s'explique soit par le fait que ces éléments avaient atteint certains de «leurs » buts, c'est-à-dire la défaite politique de leurs adversaires, soit par le fait que les tactiques extrémistes de ces mouvements étaient telles qu'il devenait difficile pour des personnes responsables de s'identifier avec eux. Certains mouvements, comme les know-nothings et l'A.P.A., se fractionnèrent parce que trop de gens en leur sein ne s'entendaient pas du tout sur les questions autres que celle qui avait justifié leur existence à l'origine. Quelques-uns d'entre eux, et en particulier le Klan, ont décliné à la suite de révélations sur les activités frauduleuses ou les rivalités de leurs dirigeants.

Même si personne n'a encore donné une explication générale valable de la courte durée des mouvements de protestation aux États-Unis, on peut avancer quelques affirmations. En premier lieu, ceux qui ont pris le chemin du « troisième parti » n'ont pu briser les contraintes qu'oppose à de telles tentatives la structure constitutionnelle américaine, qui fait de tout le pays une seule circonscription électorale lors de l'élection la plus importante, celle du président. Ces tiers partis, comme les know-nothings en 1856 et les coughlinites en 1936, aboutissent aux élections présidentielles avec un appui beaucoup moins important que celui qu'ils avaient précédemment. L'un des partis principaux fait d'habitude des avances à leurs adhérents, et plusieurs d'entre ceux-ci votent pour le «moindre mal », le jour de l'élection. Les mouvements, distincts des partis, attirent souvent des leaders et des activistes, dont la valeur et la personnalité rendent difficile le compromis sur de nouvelles questions qui confrontent le groupe. Les violentes luttes de factions qui s'ensuivent souvent aboutissent à des querelles tellement acerbes qu'elles découragent plusieurs des membres et des partisans. Ces mouvements qui adoptent des tactiques de plus en plus extrémistes voient souvent les groupes plus modérés retirer leur appui. L'Establishment, par le truchement des responsables de l'information, des élites locales et des chefs religieux et politiques; fait l'unité, en dernière instance, pour faire échec aux mouvements extrémistes qui menacent d'outrepasser les limites de ce qui est toléré par la société. Mais quelle que soit la cause du déclin, il demeure que toutes les tentatives extrémistes de ce genre ont rapidement échoué. Et même si les tensions sociales qui ont amené des millions de gens à rallier ou à suivre ces mouvements continuent d'exister, les tentatives pour prolonger ou faire revivre ceux-ci, une fois le processus de déclin commencé, ont 
invariablement échoué. Aucun d'eux n'a mis en branle un courant historique.

Ceci conclut notre brève analyse des recours aux préjugés raciaux et religieux au moyen desquels on tentait de préserver le statut ou les valeurs de groupes qui se désignaient comme les légataires de la tradition américaine; de leur point de vue, l'histoire est décevante, mais cela ne veut pas dire qu'il en sera toujours ainsi. Signalons en revanche qu'il est aujourd'hui beaucoup plus embarrassant que par le passé d'appuyer ouvertement le fanatisme. Il n'y a pas de politicien américain important qui parle de façon claire des traits négatifs de groupes minoritaires, comme le faisaient des dirigeants whigs et républicains du $\mathrm{XIX}^{\mathrm{e}}$ et du début du $\mathrm{Xx}^{\mathrm{e}}$ siècles. Rappelons que les trois présidents républicains des années 1920 - Harding, Coolidge et Hoover - ont tous exprimé, dans leurs paroles ou leurs écrits, des craintes à propos de la menace que représentaient pour les valeurs américaines celles des Américains de souche non anglo-saxonne. Sauf dans le Sud, les politiciens n'osent plus attaquer les Noirs nommément. Bien sûr, les réquisitoires racistes continuent, mais ils prennent maintenant la forme de discussions au sujet des «problèmes » créés par des groupes non identifiés. Ces changements peuvent apparaitre minimes aux yeux des habitants des ghettos, puisque des hommes qui font appel aux craintes et au fanatisme de catégories entières de la population peuvent encore se faire élire. Cependant, le fait que les politiciens des partis principaux se sentent ainsi obligés, lorsqu'ils parlent de loi et d'ordre, de mettre de l'avant un programme qui est nettement conçu pour améliorer les conditions économiques et scolaires dans le ghetto, dénote une amélioration des attitudes de l'Amérique blanche. Tous les sondages d'opinion publique concordent pour montrer qu'il y a eu un déclin des attitudes antiminoritaires manifestes, qu'elles soient dirigées contre les Noirs, les catholiques ou les Juifs. Il est remarquable, par exemple, que l'affiliation religieuse de Robert Kennedy et d'Eugene McCarthy ne fut pas mentionnée pendant la campagne de 1968.

Étant donné l'existence de sources institutionnalisées de discrimination, un tel changement des attitudes n'a encore que valeur de potentiel non exploité. Les institutions américaines sont encore biaisées en faveur des Blancs, mais le peuple américain est aujourd'hui plus disposé que jamais à exprimer sa foi dans le credo américain de l'égalité. Qu'il y croie assez profondément pour s'y conformer en pratique, c'est une autre question. La lutte pour une société vraiment égalitaire est évidemment loin d'être gagnée. Il y aura plusieurs revers, mais à long terme, l'orientation du changement demeure cohérente. Malheureusement, le rythme du changement est lent lorsqu'on le compare aux besoins. Cependant, l'on peut encore prévoir que si nous nous réunissions tous, dans dix ou vingt ans, pour discuter des types de préjugés, il y aurait encore beaucoup de preuves de la propension qu'ont les Américains à organiser la répression des groupes qui se distinguent par leurs traits raciaux, religieux ou ethniques.

La question raciale pose, bien entendu, un problème supplémentaire. Le fait que la race soit une caractéristique si manifeste, le fait que les Noirs ne peuvent devenir physiquement indistincts des autres Américains en vertu de changements dans leur éducation et leur statut occupationnel, cela veut dire, sans aucun doute, que les préjugés raciaux seront beaucoup plus difficiles à supprimer que les préjugés religieux ou ethniques. Mais on peut faire une observation encourageante au sujet des institutions politiques: le système politique ne fonctionne pas seule- 
ment comme une arène dans laquelle les tensions religieuses et raciales peuvent se manifester; il est aussi une voie que les groupes minoritaires ont utilisée d'abord symboliquement et plus tard réellement pour gagner de l'influence et améliorer leur statut. Des partis ont nommé et fait élire certains membres de groupes minoritaires qui étaient rejetés par la grande majorité, afin de gagner les voix de la minorité. Comme l'a indiqué Gunnar Myrdal, il y a un quart de siècle, plusieurs politiciens ayant personnellement des préjugés accordèrent fréquemment leur appui à cles mesures visant à promouvoir l'égalité. Élire des Noirs à de hauts postes est une excellente façon d'améliorer le statut d'un groupe traditionnellement considéré comme inférieur. Dorénavant, en plus de mesures qui visent à améliorer directement la situation économique et scolaire de la population noire, il est important que des pressions soient faites sur les deux principaux partis pour qu'ils mettent en candidature et fassent élire des dirigeants noirs. De cette façon, un chapitre nouveau et plus encourageant pourra s'insérer dans la sombre histoire de la politique et des préjugés.

À la fin de cette étude sur l'exploitation des préjugés en politique, il est important de constater que la protestation politique de droite, en Amérique, a presque toujours compté sur un courant anti-élite et souvent carrément anti-intellectuel. En dépit du fait que de tels mouvements cherchent à préserver des privilèges acquis et des valeurs traditionnelles, ils reflètent un profond engagement envers l'égalitarisme, coïncidant ainsi avec celui qui est inhérent au système de valeurs américain. Lorsque des mouvements fanatiques attaquaient les catholiques et les Juifs dans le passé, ils le faisaient en partie parce qu'ils assimilaient ces groupes à la puissance politique, économique et culturelle. Le danger que les catholiques représentaient pour l'Amérique était d'après eux le résultat d'un complot délibéré de la hiérarchie catholique et du pape qui, de concert avec les politiciens catholiques, se seraient emparés de l'Amérique pour la soumettre à la structure élitiste européenne et à ses valeurs. La menace juive allait de pair avec les activités néfastes des banquiers internationaux. Même le communisme doit être présenté comme une menace provenant de la classe riche et non de la classe pauvre. Et lorsqu'on ne pouvait prendre les élites ethniques pour cible, on dirigeait l'hostilité contre les illuminati, substituts des intellectuels.

Le récent retour de l'anti-intellectualisme, tel qu'exprimé par le mouvement de Wallace, reprend le plus vieux des thèmes du complot des populistes américains; le changement des valeurs et des institutions est attribué à des tentatives subversives délibérées de la part de l'élite intellectuelle. Il est clair, d'autre part, que les Noirs ne sont donc pas, et ne peuvent pas être assimilés à cette élite. Ils ne sont donc pas en réalité les vrais bandits; ils sont plutôt perçus comme des otages que manipulent les illuminati, les communistes ou les intellectuels afin d'atteindre des objectifs subversifs. Ceux qui sont engagés dans des mouvements contre les droits civils peuvent donc croire honnêtement qu'ils ne sont pas racistes, qu'ils ne sont pas contre les Noirs. Le pauvre noir qui veut sortir du ghetto, qui veut placer ses enfants dans une école intégrée, qui veut devenir membre des syndicats blancs n'est qu'un simple instrument qui inspire plus de pitié que de haine. Que la Birch Society, la Christian Crusade ou l'American Independent Party dirigent leur rancune contre les intellectuels plutôt que contre les Noirs n'améliore en rien la situation de ces derniers. Cela fait cependant ressortir que le fanatisme religieux et racial peut décliner en Amérique alors même que les mouvements extrémistes qui ont 
pour fonction de protéger la suprématie des Blancs et les valeurs fondamentalistes continuent d'exister. En Amérique, l'ennemi doit toujours être associé à l'élite, jamais à l'homme ordinaire, qu'il soit noir ou blanc.

\section{RÉSUMÉ}

Les extrémismes de droite qui se sont développés aux États-Unis s'expliquent par les changements continuels qui ont bouleversé la structure de la société américaine. De l'analyse historique de ces mouvements se dégage un parallélisme frappant entre les convulsions actuelles de la vie politique américaine et des périodes antérieures marquées par des montées de fanatisme religieux et racial. L'auteur établit la régularité avec laquelle ces extrémismes se sont manifestés et s'attache particulièrement au rôle joué par les préjugés et les théories du complot dans les explications présentées par ces mouvements au sujet des changements sociaux que vivait et vit encore la société américaine. Il s'attache également à élucider les conditions d'émergence de ces mouvements et invoque des raisons qui expliqueraient la courte durée de la plupart d'entre enx, alors même que les facteurs qui leur donnent naissance apparaissent comme des constantes de la vie politique américaine.

\section{ABSTRACT}

[Prejudice and Politics in the American Past and Present] Right-wing extremism in the United States is examined in relation to the continual upheavals that have shaken the American social structure. Historical analysis of these movements reveals a striking parallelism between the convulsions American political life is undergoing presently, and periods of the past that were similarly marked by waves of religious and racial fanaticism. The author establishes the regularity with which extremist movements arise, and emphasizes the recurrent themes of prejudice and supposed conspiracies that are present in the explanations given by such movements for the social changes America has undergone and continues to undergo. He sheds light also on the conditions that lead to the emergence of right-wing movements, and attempts to explain the fact that most of them declined rapidly, whereas the factors that gave rise to them appear as constants of the American political scene.

\section{RESUMEN}

[Los prejuicios y la política en los Estados Unidos de hoy y de ayer] Los movimientos de extrema derecha en los Estados Unidos son analizados en funcción de las transformaciones que han alterado constantemente la estructura de la sociedad norteamericana. El análisis historico de esos movimientos pone en evidencia un notable paralelismo entre las convulsiones actuáles de la vida política norteamericana y ciertas épocas del pasado, igualmente caracterizadas por fuentes corrientes de fanatismo religioso y racial. El autor demuestra la regularidad con que el extremismo hace su aparición, y subraya la importancia de los temas del prejuício y de la conspiración, utilizados constantemente por tales movimientos para explicar los cambios sociales que han afectado ( $y$ afectan aún hoy) a la sociedad norteamericana. Examina asimismo las condiciones que contribuyen al surgimiento de corrientes extremistas y trata de explicar el hecho de que la mayoría de esas corrientes entran rapidamente en decadencia, al tiempo que los factores que las origínan aparecen como constantes de la vida política norteamericana. 